\title{
Absolute Rate Calculations. Proton Transfers in Solution
}

\author{
Monica Barroso, Luis G. Arnaut,* and Sebastião J. Formosinho \\ Chemistry Department, University of Coimbra, P-3049 Coimbra Codex, Portugal
}

Received: August 23, 2006; In Final Form: November 28, 2006

\begin{abstract}
The reaction path of the intersecting-state model is used in transition-state theory with the semiclassical correction for tunneling (ISM/scTST) to calculate the rates of proton-transfer reactions from hydrogen-bond energies, reaction energies, electrophilicity indices, bond lengths, and vibration frequencies of the reactive bonds. ISM/scTST calculations do not involve adjustable parameters. The calculated proton-transfer rates are within 1 order of magnitude of the experimental ones at room temperature, and cover very diverse systems, such as deprotonations of nitroalkanes, ketones, HCN, carboxylic acids, and excited naphthols. The calculated temperature dependencies and kinetic isotope effects are also in good agreement with the experimental data. These calculations elucidate the roles of the reaction energy, electrophilicity, structural parameters, hydrogen bonds, tunneling, and solvent in the reactivity of acids and bases. The efficiency of the method makes it possible to run absolute rate calculations through the Internet.
\end{abstract}

\section{Introduction}

The transfer of a proton from an acid to a base

$$
\mathrm{AH}+\mathrm{B}^{-} \rightarrow \mathrm{A}^{-}+\mathrm{HB}
$$

is probably the most prevalent reaction in chemistry. The concepts of acidity and basicity are particularly well understood by chemists and the relation between these concepts and the rates of proton transfer $(\mathrm{PT})$ reactions is one of the earliest quantitative successes of chemistry. The Brönsted relation, ${ }^{1}$ Eigen's mechanism, ${ }^{2}$ Westheimer's postulate, ${ }^{3}$ and the SwainSchaad relation, ${ }^{4}$ are some of the time-honored achievements of this central field of chemistry. The present understanding of PT reactions is deeply rooted in the ideas of these authors, but old anomalies and recent developments suggest a critical evaluation of some basic concepts. The nitroalkane anomaly ${ }^{5}$ and the recent claims for an "inverted region" in PT reactions, ${ }^{6,7}$ question the application of linear free-energy relationships such as the Brönsted relation. The direct measurement of intrinsic PT rates using ultrafast excited-state proton transfers (ESPT), ${ }^{8,9}$ opens new perspectives to understand the reactivity of "normal" acids beyond the mechanism of Eigen. The limitations of the Swain-Schaad relation in evaluating the relevance of quantum mechanical tunneling from the kinetic isotope effects (KIE) of the different isotopes $\left(k_{\mathrm{H}} / k_{\mathrm{D}}\right.$ vs $\left.k_{\mathrm{H}} / k_{\mathrm{T}}\right),{ }^{10}$ requires a reassessment of tunneling corrections in PT reactions. The presence of significant tunneling also opposes Westheimer's interpretation of KIE solely in terms of zero-point energy (ZPE) changes, but both tunneling and ZPE must be reconciled with the observation of a maximum $\mathrm{KIE}\left(=k_{\mathrm{H}} / k_{\mathrm{D}}\right)$ ca. 4 for PT between oxygen atoms in aqueous solutions, ${ }^{11}$ less than half of the maximum observed for PT involving carbon atoms.

The objective of this work is to relate the electronic and molecular structure of acids and bases with the corresponding PT rates. We wish to provide quantitative, yet simple, answers to fundamental questions such as the following: Why is the rate of the acid-catalyzed dedeuteration of azulene-1- $d\left(\mathrm{p} K_{\mathrm{a}}=\right.$

* Corresponding author. E-mail: 1garnaut@ci.uc.pt.
-1.76) $0.45 \mathrm{M}^{-1} \mathrm{~s}^{-1},{ }^{12}$ whereas the deprotonation rate of 5-cyano-1-naphthol ( $\left.\mathrm{p} K_{\mathrm{a}}=-2.7\right)$ is $1.3 \times 10^{11} \mathrm{~s}^{-1},{ }^{13}$ when both of them are measured in water $\left(\mathrm{p} K_{\mathrm{a}}=-1.74\right)$ ? Why is $k_{\mathrm{H}} / k_{\mathrm{D}}=11$ for the detritiation of toluene $\left(\mathrm{p} K_{\mathrm{a}}=41.2\right)$ by cesium cyclohexylamine $\left(\mathrm{p} K_{\mathrm{a}}=41.6\right)$ in cyclohexylamide, ${ }^{14}$ whereas for the deprotonation of 5-cyano-1-naphthol in water it is only $1.6 ?^{13}$ The answer to such questions can only be found in the framework of a theoretical model that is sufficiently accurate to reproduce the experimental data without adjustable parameters, and yet sufficiently simple to be applied to complex systems without loosing its physical insight.

The intersecting-state model (ISM), ${ }^{15,16}$ provides a fertile ground to explore the relations between the structure of the reactants and the energy of the transition state. ${ }^{17,18}$ ISM, in its more recent formulation in terms of interacting states, ${ }^{19,20}$ when combined with TST, provides fast and reliable estimates for the absolute rates of very different atom transfers, using only information on the reactants and products. We employ the term "absolute" to mean that the actual rate constants are calculated exclusively from thermodynamic and spectroscopic information on the reactants and products. The calculations do not involve the fitting of any parameters to the kinetic data. In this work, we present the modifications of ISM required to make absolute rate calculations of proton transfers in solution. As in the formulation for atom transfers, the present application relies exclusively in relations that lie outside the field of reaction kinetics and has no adjustable parameters, except those involved in the empirical potentials used in the model. The fundamental equations of ISM are presented below. The complete formalism can be found in the Supporting Information. A computer program running an ISM implementation in the Java programming language can be accessed. ${ }^{127}$

\section{Methods}

2.1. Non-Hydrogen-Bonded Systems. The PT step in carbon acid or base catalysis in solution can be described as an elementary reaction going through a transition state

$$
\mathrm{AH}+\mathrm{B}^{-} \rightleftharpoons\{\mathrm{A} \cdots \mathrm{H} \cdot \cdot \mathrm{B}\}^{-\ddagger} \rightarrow \mathrm{A}^{-}+\mathrm{HB}
$$


Assuming the conservation of the bond order along the reaction coordinate $^{21}$

$$
n=n_{\mathrm{HB}}=1-n_{\mathrm{HA}}
$$

where $n_{\mathrm{HA}}$ and $n_{\mathrm{HB}}$ are the reactant and product bond-orders, respectively, ISM generalizes the Pauling relation, ${ }^{22}$ originally formulated for equilibrium bond orders and bond lengths ( $l_{\mathrm{HA}, \mathrm{eq}}$, $\left.l_{\mathrm{HB}, \mathrm{eq}}\right)$, to transition-state bond orders $\left(n^{\ddagger}{ }_{\mathrm{AH}}, n^{\ddagger}{ }_{\mathrm{BH}}\right)$ and bond lengths ${ }^{15,16}$

$$
\begin{aligned}
& l_{\mathrm{HA}}^{\ddagger}-l_{\mathrm{HA}, \mathrm{eq}}=-a_{\mathrm{sc}}^{\prime}\left(l_{\mathrm{HA}, \mathrm{eq}}+l_{\mathrm{HB}, \mathrm{eq}}\right) \ln \left(n_{\mathrm{HA}}^{\ddagger}\right) \\
& l_{\mathrm{HB}}^{\ddagger}-l_{\mathrm{HB}, \mathrm{eq}}=-a_{\mathrm{sc}}^{\prime}\left(l_{\mathrm{HA}, \mathrm{eq}}+l_{\mathrm{HB}, \mathrm{eq}}\right) \ln \left(n_{\mathrm{HB}}^{\ddagger}\right)
\end{aligned}
$$

The scaling by $a_{\mathrm{sc}}^{\prime}\left(l_{\mathrm{AB}, \mathrm{eq}}+l_{\mathrm{BC}, \mathrm{eq}}\right)$ reflects the fact that longer bonds will stretch out more from equilibrium to the transitionstate configurations than shorter ones, and that two bonds are implicated in the transition state. The value of $a_{\mathrm{sc}}^{\prime}$ was obtained from the bond extension of the $\mathrm{H}+\mathrm{H}_{2}$ system, ${ }^{23} a_{\mathrm{sc}}^{\prime}=0.182$.

The saturation point for electron inflow in the transition state is incorporated in ISM using the electrophilicity index of Parr, ${ }^{24}$ $m$, which is the ratio between the negative of the electronic chemical potential, $\mu_{\mathrm{el}}$, and the chemical hardness, $\eta_{\mathrm{el}}$

$$
m=\frac{-\mu_{\mathrm{el}}}{\eta_{\mathrm{el}}}=\frac{I_{\mathrm{P}}+E_{\mathrm{A}}}{I_{\mathrm{P}}-E_{\mathrm{A}}}
$$

where $I_{\mathrm{P}}$ is the ionization potential and $E_{\mathrm{A}}$ is the electron affinity of $\mathrm{A}$ or $\mathrm{B}$. The value of $m$ can be calculated from the electronic parameters of $\mathrm{A}$ or $\mathrm{B}$, but each transition state can only have one value of $m$. We assume that, for each proton transfer, the value of $m$ at the transition state is determined by the electronic properties of the species with the lowest $I_{\mathrm{P}}$, because it is easier to delocalize the electrons of that species. The electrophilicity index $m$ is also a measure of resonance at the transition state.

Using these relations, the effective Morse curves representing the $\mathrm{AH}$ and $\mathrm{BH}$ bonds can be written ${ }^{19,25}$

$$
\begin{aligned}
& V_{\mathrm{HA}}=D_{\mathrm{e}, \mathrm{HA}}\left\{1-\exp \left[\beta_{\mathrm{HA}} a_{\mathrm{sc}}^{\prime}\left(l_{\mathrm{HA}, \mathrm{eq}}+l_{\mathrm{HB}, \mathrm{eq}}\right) \ln \left(n_{\mathrm{HA}}\right) / m\right]\right\}^{2} \\
& V_{\mathrm{HB}}=D_{\mathrm{e}, \mathrm{HB}}\left\{1-\exp \left\{\beta_{\mathrm{HB}} a_{\mathrm{sc}}^{\prime}\left(l_{\mathrm{HA}, \mathrm{eq}}+l_{\mathrm{HB}, \mathrm{eq}}\right) \ln \left(n_{\mathrm{HB}}\right) / m\right]\right\}^{2}
\end{aligned}
$$

where $D_{\mathrm{e}, \mathrm{HA}}$ and $D_{\mathrm{e}, \mathrm{HB}}$ are the electronic dissociation energies, and $\beta_{\mathrm{HA}}$ and $\beta_{\mathrm{HB}}$ the spectroscopic constants of the bonds $\mathrm{HA}$ and HB. The value of $m$ changes smoothly from 1 in the reactants to the value given by eq 3 at the transition state and back to 1 in the products. The switching function that produces this variation along the reaction coordinate is given in the Supporting Information, but its form is irrelevant for the calculation of the transition state configuration and energy.

The classical reaction path of ISM is a linear interpolation between the Morse curves of HA and HB along the reaction coordinate

$$
V_{\mathrm{cl}}(n)=(1-n) V_{\mathrm{HA}}+n V_{\mathrm{HB}}+n \Delta V^{0}
$$

where the classical reaction energy is

$$
\begin{array}{r}
\Delta V^{0}=-R T\left(2.303 \mathrm{p} K_{\mathrm{AH}}+\ln \left(p_{\mathrm{A}} / q_{\mathrm{A}}\right)-2.303 \mathrm{p} K_{\mathrm{BH}}-\ln \right. \\
\left.\left(p_{\mathrm{B}} / q_{\mathrm{B}}\right)\right)-Z_{\mathrm{AH}}+Z_{\mathrm{BH}}
\end{array}
$$

$\mathrm{p} K_{\mathrm{AH}}$ and $\mathrm{p} K_{\mathrm{BH}}$ are the thermodynamic acidity constants of $\mathrm{AH}$ and $\mathrm{BH}, p_{\mathrm{A}}\left(p_{\mathrm{B}}\right)$ is the number of equivalent protons in $\mathrm{AH}$ $(\mathrm{BH}), q_{\mathrm{A}}\left(q_{\mathrm{B}}\right)$ is the number of equivalent basic sites in $\mathrm{AH}$
$(\mathrm{BH})$, and $Z_{\mathrm{AH}}\left(Z_{\mathrm{BH}}\right)$ is the zero-point energy of the $\mathrm{AH}(\mathrm{BH})$ bond. This reaction coordinate is very convenient because it only requires information along one dimension, and, although is not based on a theory of a deeper level, has been shown to give a good representation of the minimum-energy path of various systems. ${ }^{26-28}$ Additionally, eq 6 introduces the correct free-energy difference between reactants and products in the vibrationally adiabatic path used for rate constant calculations. This definition of the reaction energy differs from that previously employed for atom transfers in the gas phase, for which $\Delta V^{0}=$ $D_{\text {e,HA }}-D_{\text {e,HB. }}{ }^{19}$

The vibrationally adiabatic path is calculated adding the difference in ZPE to the classical energy at each point along the reaction path

$$
V_{\mathrm{ad}}(n)=V_{\mathrm{cl}}(n)+\sum_{i}\left(\frac{1}{2} h c \bar{v}_{i}\right)
$$

where $\bar{v}_{i}$ are the vibration frequencies of the normal modes orthogonal to the reaction coordinate. We estimate the frequencies of the linear triatomic transition state from Wilson's equation with the neglect of the interaction between bending and stretching, ${ }^{29}$ using fractional bonds in the $\{\mathrm{A} \cdots \mathrm{B} \cdots \mathrm{C}\}^{\ddagger}$ transition state and a switching function to provide the correct asymptotic limits. ${ }^{19}$ The linear relation between symmetric stretching and bending frequencies in triatomic systems is employed to estimate the bending frequency from the symmetric stretching frequency. ${ }^{30}$

The vibrationally adiabatic barrier, $\Delta V^{\ddagger}$ ad, is inserted in the transition-state expression for the reaction rate, together with the partition functions for the transition state $\left(Q_{\ddagger}\right)$ and reactants $\left(Q_{\mathrm{B}}, Q_{\mathrm{HA}}\right)$, and leads to the semi-classical rate constant

$$
k_{\mathrm{sc}}=\kappa(T) \frac{k_{\mathrm{B}} T}{h}\left(\frac{1}{3}\right)^{3} \frac{Q_{\ddagger}}{Q_{\mathrm{B}} Q_{\mathrm{HA}}} \exp \left(-\frac{\Delta V_{\mathrm{ad}}^{\ddagger}}{R T}\right)
$$

where $\kappa(T)$ is the semiclassical tunneling correction along the vibrationally adiabatic path, and the scaling factor $(1 / 3)^{3}$ was obtained from the typical ratio of vibrational to rotational partition functions in polyatomic reactants. ${ }^{19,30}$ This scaling is only appropriate for reactions following mechanism II, where specific interactions (H-bonding, Coulombic forces) between the two reactants are negligible, and the reaction frequency in solution approaches that of polyatomic reactant in the gas phase. This mechanism presumes that the rate-determining step of the proton-transfer reaction is bimolecular, in agreement with the rate constant expressed by eq 8 , which is in units of $\mathrm{M}^{-1} \mathrm{~s}^{-1}$.

The moment of inertia of HA is twice as large as that of DA. Although this is true when $\mathrm{A}$ and $\mathrm{B}$ are atoms and the reaction takes place in the gas phase, it introduces an unrealistic factor of 2 for KIE calculations in condensed phases. Bell has shown that the ratio of pre-exponential factors for proton and deuteron transfer should lie between $1 / 2$ (classical, high-temperature limit for all frequencies) and $\sqrt{ } 2$ (classical limit for the transition state frequencies only). ${ }^{31}$ In this work, we will use identical pre-exponential factors for the transfer of all the hydrogen isotopes.

2.2. Hydrogen-Bonded Systems. The mechanism for proton transfer between strong acids and bases involves hydrogenbonded intermediates. According to the mechanism proposed by Eigen, ${ }^{2}$ and adopted by many authors, ${ }^{32}$ we have to consider 
a precursor and a successor complex along the reaction coordinate

$$
\mathrm{AH}+\mathrm{B}^{-} \underset{k_{-\mathrm{a}}}{\stackrel{k_{\mathrm{a}}}{\rightleftharpoons}} \mathrm{AH} \cdots \mathrm{B}^{-} \underset{k_{-\mathrm{p}}}{\stackrel{k_{\mathrm{p}}}{\rightleftharpoons}} \mathrm{A}^{-} \cdots \mathrm{HB} \underset{k_{-\mathrm{d}}}{\stackrel{k_{\mathrm{d}}}{\rightleftharpoons}} \mathrm{A}^{-}+\mathrm{HB}
$$

We include such complexes using the Lippincott-Schroeder (LS) potential. ${ }^{33}$ The LS potential relates the H-bond binding energies $\left(D_{\mathrm{AB}}\right)$ to the $\mathrm{AB}$ equilibrium distances $\left(l_{\mathrm{AB}, \mathrm{eq}}\right)$ and to $\mathrm{AB}$ stretching frequency $\left(\bar{v}_{\mathrm{AB}}\right)$ in the $\mathrm{B} \cdots \mathrm{H}-\mathrm{A}$ hydrogenbonded complex (charges omitted). It is the sum of four terms

$$
V_{\mathrm{LS}}=V_{\mathrm{HA}}+V_{\mathrm{HB}}+V_{\mathrm{rep}}+V_{\mathrm{el}}
$$

where the first two terms represent covalent interactions, the third term is a repulsion and the last one is the electrostatic interaction. The covalent terms have forms analogous to that of a Morse potential and together require one adjustable parameter to fit one $\mathrm{AH}$ vibrational frequency shift or one AH bond length. This parameter establishes the relation

$$
D_{\mathrm{H} \cdots \mathrm{B}}=D_{\mathrm{HA}} / g
$$

where $D_{\mathrm{HA}}$ and $D_{\mathrm{H} \cdots \mathrm{B}}$ are the bond-dissociation energies of the unperturbed HA and $\mathrm{H} \cdots \mathrm{B}$ bonds. Lippincott and Schroeder found that a suitable value for $g$ is 1.45 . We also employ this value.

The repulsive term is a negative exponential and the electrostatic one is a negative power of the $\mathrm{AB}$ distance. Both these terms involve empirical constants. They are modified to reduce the number of constants and the only remaining unknown is a repulsion constant $b$, which can be evaluated through the use of one known hydrogen bond energy. Lippincott and Schroeder chose $b=4.8 \AA$ to obtain the best agreement with the $\mathrm{H}$-bond energies available at their time, and added a correction of $3 R T / 2$ for the change in degrees of freedom on dissociation of the hydrogen bond. In the following section, we reevaluate the fitting of $b$ in terms of the energies presently available.

As demonstrated elsewhere, ${ }^{20}$ the inclusion of the LS potential along the ISM reaction coordinate only requires the knowledge of either the H-bond energy $\left(D_{0(\mathrm{AHB})}\right)$, the $\mathrm{AB}$ distance $\left(l_{\mathrm{AB}}\right)$ or the stretching frequency of the heavy atoms $\left(\omega_{\mathrm{e}(\mathrm{AB})}\right)$ in the H-bonded complex. These three parameters are related by the LS potential, and the knowledge of one of them gives the other two. The H-bonded complex is an incipient proton transfer, with a significant bond order between the proton and the base $\left(n_{\mathrm{H} \cdots \mathrm{B}}>0.1\right)$. The presence of such a complex in the reaction coordinate reduces the height and the width of the barrier. ${ }^{30}$

In solution, we need only to consider the path between the minimum of the precursor complex and that of the successor complex. The energy barrier is the difference between the maximum along that path (i.e., the transition state energy) and the minimum of the precursor complex. We assume that the proton is transferred along the hydrogen bond between the acid and the base, much in the same manner as in the model proposed by Weiss. ${ }^{34}$ This author employed as the frequency factor of the PT step, the product between the stationary concentration of the H-bonded collision complexes for unit concentration of the two reactants, multiplied by a frequency given by the reactive
CHART 1. Excited-State Proton Transfer in Naphthols

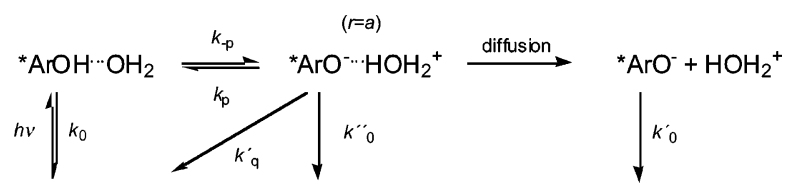

hydrogen bond. According to mechanism III, rate-limiting PT $\left(k_{-\mathrm{a}} \gg k_{\mathrm{p}}\right.$ and $\left.k_{\mathrm{d}} \gg k_{-\mathrm{p}}\right)$ have

$$
\begin{gathered}
k_{\mathrm{f}}=\frac{k_{\mathrm{a}}}{k_{-\mathrm{a}}} k_{\mathrm{p}} \\
k_{r}=\frac{k_{-\mathrm{d}}}{k_{\mathrm{d}}} k_{-\mathrm{p}}
\end{gathered}
$$

Applications of this mechanism have employed $k_{\mathrm{a}} / k_{-\mathrm{a}}$ and $k_{\mathrm{d}} /$ $k_{-\mathrm{d}}$ ratios between 0.1 and $0.12 \mathrm{M}^{-1} .32 \mathrm{In}$ our calculations we employ as pre-exponential factor the product of the association constant $K_{\mathrm{c}}$ by the frequency of the promoting mode of PT in $\mathrm{H}$-bonded systems. The promoting mode is the stretching frequency of the heavy atoms $\left(\omega_{\mathrm{e}(\mathrm{AB})}\right)$. In water, this is the vibration of an oxygen atom against its nearest neighbor oxygen when a hydrogen bond is present between them, and has been described as a restricted translation of $\mathrm{H}_{2} \mathrm{O}$ molecules. ${ }^{35}$ When tunneling corrections are included, the final form of the rate constant in $\mathrm{H}$-bonded systems is

$$
k=\kappa(T) c \omega_{\mathrm{e}(\mathrm{AB})} K_{\mathrm{c}} \exp \left(-\frac{\Delta V_{\mathrm{ad}}^{\ddagger}}{R T}\right)
$$

where $c$ is the speed of light in vacuum and $K_{\mathrm{c}}$ represents the fraction of acid species $\mathrm{H}$-bonded to the base. For all the systems studied in this work, $v=\mathrm{c} \omega_{\mathrm{e}(\mathrm{AB})}$ is numerically very close to the usual frequency factor of transition-state theory at room temperature, $6 \times 10^{12} \mathrm{~s}^{-1}$. We recall that original meaning of $k_{\mathrm{B}} T / h$ is the "effective rate of crossing the energy barrier by the activated complexes". ${ }^{36}$ For H-bonded systems oriented along the reaction path, this rate of crossing can be meaningfully replaced by the frequency of the promoting mode, because it gives more precisely the frequency of the motion along the reaction path. Stahl and Jencks evaluated the data for the intermolecular hydrogen bonding of oxygen acids in water and concluded that the association constants of formic acid-formate, acetic acid-acetate, and acetic acid-phenolate are $K_{\mathrm{c}}=0.12$, 0.14 , and $0.39 \mathrm{M}^{-1}$, respectively. ${ }^{37}$ This association constant is a measure of the difference in H-bonding ability to two acids, not the absolute strength of hydrogen bonding. This is due to the competition between intermolecular $\mathrm{H}$-bonding between solutes and hydrogen bonding to water. Increasing the hydrogen bonding ability of the solute does not lead to a net increase in the H-bonding between solutes with respect to water. The hydrogen bifluoride ion, $\mathrm{FHF}^{-}$, with an association constant of $4 \mathrm{M}^{-1,38}$ is an "anomaly". In view of these values and of the typical $k_{\mathrm{a}} / k_{-\mathrm{a}}$ and $k_{\mathrm{d}} / k_{-\mathrm{d}}$ ratios, ${ }^{32}$ we will use $K_{\mathrm{c}}=0.1 \mathrm{M}^{-1}$ for bimolecular PT between $\mathrm{H}$-bonded oxygen acids and bases, when one of them is in an ionic form.

The last case to be considered is proton transfer to, or from, the solvent. This has been studied in great detail for photoacids, such as electronically excited naphthols, in water. It was shown that the rate of proton transfer is dependent not on water molarity, but on solvent intramolecularity. ${ }^{39}$ Chart 1 accommodates the kinetic and thermodynamic data on the protolytic photodissociation of hydroxyaromatic photoacids. The deprotonation rate constant, $k_{-\mathrm{p}}$, is first-order and leads to a contact 
TABLE 1: Bond Lengths, Enthalpies, and Frequencies of H-Bonds between Oxygen Atoms

\begin{tabular}{lllc}
\hline & $l_{\mathrm{OO}}(\AA)$ & $\Delta H_{\mathrm{OO}}(\mathrm{kcal} / \mathrm{mol})$ & $\omega_{\mathrm{e}(\mathrm{AB})}\left(\mathrm{cm}^{-1}\right)$ \\
\hline $\mathrm{HOH}-\mathrm{OH}$ (gas) a) & $3.03^{45}$ & $3.51^{b, 46}$ & \\
$\left(\mathrm{H}_{2} \mathrm{O}\right)_{2}$ (gas) & $2.914^{47}$ & $3.50^{47}$ & \\
$\left(\mathrm{H}_{2} \mathrm{O}\right)_{2}$ (aq.) & $2.85^{42}$ & $2.53 \pm 0.10^{41}$ & $170^{35}$ \\
$\left(\mathrm{H}_{2} \mathrm{O}\right)_{2}$ (ice I) & $2.76^{48}$ & $5.19^{49}$ & $220^{48}$ \\
$\left(\mathrm{CH}_{3} \mathrm{OH}\right)_{2}$ (gas) & $2.873^{50}$ & $3.2^{51}$ & \\
$\left(\mathrm{CH}_{3} \mathrm{COOH}\right)_{2}$ & $2.68^{52}$ & $7^{c, 53}$ & \\
$\mathrm{H}_{3} \mathrm{O}_{2}{ }^{-}$(gas) & $2.47^{54}$ & $26.5^{43}$ & \\
$\left(\mathrm{CH}_{3} \mathrm{OHOCH}\right)^{-}$(gas) & $2.425^{d, 55}$ & $22-28.8^{56,57}$ & \\
$\mathrm{H}_{5} \mathrm{O}_{2}{ }^{+}$(gas) & $2.38^{44}$ & $31.8^{43}$ & $650^{58}$
\end{tabular}

${ }^{a}$ Structure where the water molecule is the hydrogen donor. ${ }^{b}$ This is the electronic H-bond dissociation energy. ${ }^{c}$ Half of the enthalpy of the ring dimer, which is almost identical to the enthalpy of the most stable open dimer. ${ }^{53}{ }^{d}$ In the H-bonded binuclear complex trisodium trihydrogen bis[tris(glycolato)aluminate(III)].

ion pair with a radius $a$, that subsequently diffuses apart. The rate constant for this step can be expressed as in eq 12, making $K_{\mathrm{c}}=1$, because all the $\mathrm{ArOH}$ moieties are hydrogen-bonded to the solvent. Thus, in this work, proton transfers in hydrogenbonded systems are treated as intramolecular reactions.

The treatment of $\mathrm{H}$-bonded systems as intramolecular PT leads to the calculation of first-order rates. The experimental data on PT to water usually reports first-order rates that are directly comparable with the calculated values. However, the reverse reaction, which might involve the conjugate base and the hydronium ion, is usually reported in the units of a bimolecular reaction, $\mathrm{M}^{-1} \mathrm{~s}^{-1}$. The comparison between the two can be made dividing the calculated rate, in $\mathrm{s}^{-1}$, by $\left[\mathrm{H}_{2} \mathrm{O}\right]=$ $55 \mathrm{M}$. The consistence between theory and experiment is achieved including the concentration of water in the equilibrium constant, in the old physical-organic chemistry tradition. ${ }^{40}$

2.3. Hydrogen-Bond Energies. It is definitively established that the enthalpy of the hydrogen bond in liquid water is 2.53 $\pm 0.10 \mathrm{kcal} / \mathrm{mol},{ }^{41}$ that the near-neighbor $\mathrm{H}_{2} \mathrm{O} \cdots \mathrm{OH}_{2}$ distance in the tetrahedral network of pure water is $l_{\mathrm{OO}}=2.85 \AA,{ }^{42}$ and that the vibrational frequency of the H-bond stretching is $\omega_{\mathrm{e}}(\mathrm{AB})$ $=170 \mathrm{~cm}^{-1} \cdot{ }^{35}$ Using $D_{0 \text { (water) }}=2.0 \mathrm{kcal} / \mathrm{mol}$, the LS potential gives the electronic $\mathrm{H}$-bond energy $D_{\mathrm{e}(\text { water })}=2.56 \mathrm{kcal} / \mathrm{mol}$, $l_{\mathrm{OO}}=2.80 \AA$, and $\omega_{\mathrm{e}(\mathrm{AB})}=163 \mathrm{~cm}^{-1}$. The experimental gasphase $\mathrm{H}$-bond enthalpy of $\mathrm{H}_{5} \mathrm{O}_{2}{ }^{+}$is also known, $31.8 \mathrm{kcal} / \mathrm{mol}$, ${ }^{43}$ as well as its $\mathrm{O} \cdots \mathrm{O}$ distance of $2.38 \AA .{ }^{44}$ Using $D_{0\left(\mathrm{H}_{5} \mathrm{O}_{2}{ }^{+}\right)}=23$ $\mathrm{kcal} / \mathrm{mol}$, the LS potential gives $D_{\mathrm{e} \text { (water) }}=27 \mathrm{kcal} / \mathrm{mol}, l_{\mathrm{OO}}=$ $2.36 \AA$ and $\omega_{\mathrm{e}(\mathrm{AB})}=1067 \mathrm{~cm}^{-1}$. For $D_{0\left(\mathrm{H}_{5} \mathrm{O}_{2}{ }^{+}\right)}>25 \mathrm{kcal} / \mathrm{mol}$ the double-well potential merges into a single well. Other experimental data on hydrogen bonds between oxygen atoms are collected in Table 1 and compared with the LS potential in Figure 1. According to the LS potential, the $\mathrm{O} \cdots \mathrm{O}$ distances are approximately linearly related to the logarithm of the H-bond energies, and the agreement with the experimental data confirms the good performance of the LS potential. ${ }^{20}$ This agreement is improved when the repulsion constant $b$ is increased to $9.0 \AA$, as shown in that figure. However, the proton-transfer rates, to be discussed further below, change by less than a factor of 2 when $b$ is increased from 4.8 to $9.0 \AA$. We opted for the original calibration to emphasize the fact that our calculations are not biased by an arbitrary choice of parameters.

The nature of the hydrated proton and its mobility in liquid water has been subject to much controversy. ${ }^{59,60}$ Eigen proposed an entity where the central oxonium ion is strongly $\mathrm{H}$-bonded to three $\mathrm{H}_{2} \mathrm{O}$ molecules, $\mathrm{H}_{3} \mathrm{O}^{+}\left(\mathrm{H}_{2} \mathrm{O}\right)_{3}$, ${ }^{2}$ but Zundel argued for the relevance of the $\left(\mathrm{H}_{2} \mathrm{O}-\mathrm{H}^{+} \cdot . \cdot \mathrm{OH}_{2}\right)$ ion at small degrees of hydration. ${ }^{61}$ The Eigen ion was observed by Triolo and Narten using X-ray and neutron scattering, and $l_{\mathrm{OO}}\left(\mathrm{H}_{3} \mathrm{O}^{+} \cdots \mathrm{OH}_{2}\right)=$

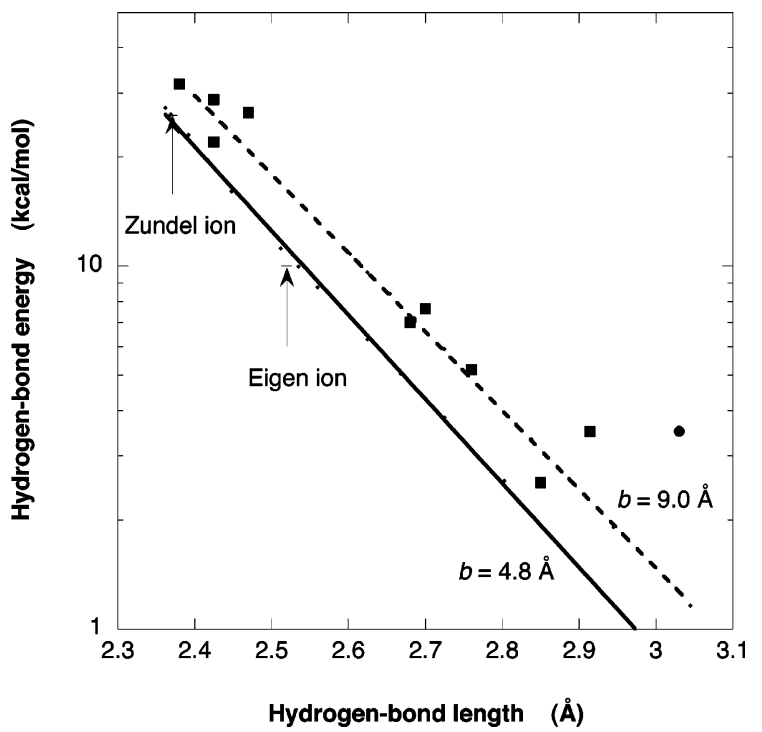

Figure 1. Relation between the enthalpies (squares) and electronic energy (circle) of hydrogen bonds and the corresponding $\mathrm{O} \cdots \mathrm{O}$ distances, using data from Table 1 . The lines represent the relations predicted by the Lippincott-Schroeder potential using the values of the repulsion parameter indicated in the plot. The electronic energies of the $\mathrm{H}$-bonds in Eigen and Zundel ions, anticipated form their $\mathrm{O} \cdots \mathrm{O}$ distances, are also indicated in the plot.

$2.52 \AA$ was measured. ${ }^{42}$ The LS potential with $D_{0(\mathrm{O}+\mathrm{HO})}=8$ $\mathrm{kcal} / \mathrm{mol}$, gives $l_{\mathrm{O}+\mathrm{O}}=2.535 \AA$ and $\omega_{\mathrm{e}(\mathrm{OO})}=562 \mathrm{~cm}^{-1}$. However, the neutron diffraction measurements of Kameda and co-workers on aqueous $21 \% \mathrm{HCl}$ solutions, revealed a nearest neighbor $\mathrm{O} \cdots \mathrm{O}$ distance of $2.37 \pm 0.02 \AA$, consistent with the Zundel ion. This distance in the LS potential corresponds to $D_{0(\mathrm{O}+\mathrm{HO})}=22 \mathrm{kcal} / \mathrm{mol}$ and $\omega_{\mathrm{e}(\mathrm{OO})}=1052 \mathrm{~cm}^{-1}$. The extraordinary strength of the $\mathrm{H}$-bond in the Zundel ion is consistent with the experimental gas-phase $\mathrm{H}$-bond enthalpy of $\mathrm{H}_{5} \mathrm{O}_{2}{ }^{+}, 31.8 \mathrm{kcal} / \mathrm{mol},{ }^{43}$ and its $\mathrm{O} \cdots \mathrm{O}$ distance of $2.38 \AA .{ }^{44}$ This is not incompatible with a fast equilibrium with Eigen ion in water, because the latter can form three H-bonds worth ca. 8 $\mathrm{kcal} / \mathrm{mol}$ each.

The ISM reaction coordinate for proton transfer in water coincides with the Zundel ion. Using the $\mathrm{O} \cdots \mathrm{O}$ distance of 2.37 $\pm 0.02 \AA$, the proton movement between the two $\mathrm{H}_{2} \mathrm{O}$ moieties of the Zundel ion only has to cross a small and thin barrier, with a $0.12 \AA$ width. Using the parameters of $\mathrm{H}_{2} \mathrm{O}$ presented in Table 2, we estimate a 160 fs proton-transfer time with a tunneling correction factor of 1000. It is relevant to emphasize that using the ionization potential of liquid water proposed by Mozumder, $I_{\mathrm{P}}=11.7 \mathrm{eV}$, and assuming that the electron affinity value for water is the electron hydration energy, $E_{\mathrm{A}}=1.65 \mathrm{eV},{ }^{62}$ we obtain indistinguishable results, which reflect the stability of our calculations with respect to small changes in the parameters of the reactants. The calculated proton-transfer rates are much faster than the picosecond proton mobility in liquid water. This is consistent with the current view on the proton mobility, which assigns its rate-determining step to changes in the second hydration shell of the Zundel ion. ${ }^{63}$ Agmon offered a bond-order analysis for the cooperative many-molecule effects related to the proton mobility in liquid water. ${ }^{60}$ Such an analysis exceeds the scope of the present work, that focus exclusively on the concerted bond-breaking-bond-forming event attending the direct transfer of a proton from an acid to a base. On the proton mobility in water, we can only state that it is not ratedetermined by proton tunneling within the Zundel ion.

McAllister and co-workers recently used high-level $a b$ initio calculations incorporating cavity polarity effects to estimate the 
TABLE 2: Bond Lengths, Bond Dissociation Energies, Vibrational Frequencies of the Molecules, and Ionization Potentials and Electron Affinities of the Radicals Employed in the Calculation of the Energy Barriers of Atom and Proton Transfer Reactions ${ }^{a}$

\begin{tabular}{llcccl}
\hline & $l_{\mathrm{eq}}(\AA)$ & $D^{0}{ }_{298}\left(\mathrm{kcal} \mathrm{mol}^{-1}\right)$ & $\omega_{\mathrm{e}}\left(\mathrm{cm}^{-1}\right)$ & $I_{\mathrm{P}}(\mathrm{eV})$ & $E_{\mathrm{A}}(\mathrm{eV})$ \\
\hline $\mathrm{C}_{6} \mathrm{H}_{6}$ & 1.101 & 113.1 & 3062 & 8.32 & 1.096 \\
$\mathrm{CH}_{3} \mathrm{C}_{6} \mathrm{H}_{5}$ & 1.111 & 89.8 & $2934^{b}$ & 7.242 & 0.912 \\
azulene & & & & $7.42^{c}$ & $0.79^{c}$ \\
$\mathrm{CH}_{3} \mathrm{COCH}_{3}$ & 1.103 & 98.3 & 2939 & $9.703^{c}$ & $1.76^{d}$ \\
$\mathrm{CH}_{3} \mathrm{NO}_{2}$ & 1.088 & 60.8 & 3048 & $11.08^{c}$ & $0.50^{c}$ \\
$\mathrm{HCN}$ & 1.0655 & 126.1 & 3311 & 14.170 & 3.862 \\
$\mathrm{CH}_{3} \mathrm{NH}_{2}$ & 1.099 & 93.3 & 2820 & 6.29 & \\
$\mathrm{CH}_{3} \mathrm{NH}_{2}$ & 1.010 & 100.0 & 3361 & $8.9^{c}$ & \\
$\mathrm{H}_{2} \mathrm{O}$ & 0.9575 & 119.0 & 3657 & 13.017 & 1.8277 \\
$\mathrm{CH}_{3} \mathrm{COOH}$ & 0.97 & 105.8 & 3583 & $10.65^{c}$ & $3.29^{d}$ \\
$\mathrm{C}_{6} \mathrm{H}_{5} \mathbf{O H}$ & 0.956 & 86.5 & 3650 & 8.56 & 2.253
\end{tabular}

${ }^{a}$ Gas-phase data; boldface letters indicate where the radical is centered after the bond to the hydrogen atom is broken; bond lengths and bond dissociation energies from ref 71 ; ionization potentials and electron affinities from webbook.nist.gov, except where noted. ${ }^{b}$ Reference 72. ${ }^{c}$ For the molecule. ${ }^{d}$ Reference 73.

strength of hydrogen bonds in water. ${ }^{64}$ They obtained a H-bond energy of $2.6 \mathrm{kcal} / \mathrm{mol}$ for the formic acid-formic acid complex and $7.2 \mathrm{kcal} / \mathrm{mol}$ for the formic acid-formate anion complex. This estimate is in reasonable agreement with the activation energy for proton exchange between maleic acid and hydrogen maleate in $10 \%$ water/acetone- $d_{6}$, which is consistent with a ca. $4 \mathrm{kcal} / \mathrm{mol}$ stronger intermolecular $\mathrm{H}$-bond in the hydrogen maleate than the conventional $\mathrm{H}$-bond in aqueous solution. ${ }^{65}$ However, the equilibrium constants between cis and trans isomers of hydrogen maleate vs maleic acid in water suggest that the intermolecular H-bond in the monoanion is only 0.5 $\mathrm{kcal} / \mathrm{mol}$ more stable than the conventional H-bond. These studies place the enthalpy of the H-bond between an oxygencentered anion and water in the $3-7 \mathrm{kcal} / \mathrm{mol}$ range. In this work we adopt $D_{0(\mathrm{OHO})}=2.0 \mathrm{kcal} / \mathrm{mol}$ for hydrogen bonds between uncharged oxygen atoms and $D_{0\left(\mathrm{O}^{-} \mathrm{H}\right)}=4 \mathrm{kcal} / \mathrm{mol}$ for H-bonds between carboxylate or phenonate anions and neutral oxygen acids. A similar $2 \mathrm{kcal} / \mathrm{mol}$ increase in the energy of an hydrogen bond between uncharged to single-charged oxygen atoms was also proposed by Agmon. ${ }^{66}$

$\mathrm{H}$-bonding to carbon acids is less important than to oxygen or nitrogen acids and, in aqueous solutions, can be neglected. A possible exception is $\mathrm{HCN}$, which forms dimers at low temperatures. With $D_{0}=1.5 \mathrm{kcal} / \mathrm{mol}$ for the $\mathrm{HCN}$ dimer, we obtain a $(\mathrm{N} \cdots \mathrm{C})$ distance of $3.246 \AA$, a H-bond stretching frequency of $194 \mathrm{~cm}^{-1}$, and an electronic H-bond energy $D_{\mathrm{e}}=$ $2.16 \mathrm{kcal} / \mathrm{mol}$, which compare reasonably well with the experimental values of $3.287 \AA, 120 \mathrm{~cm}^{-1}$ and $1.9 \mathrm{kcal} / \mathrm{mol}{ }^{67,68}$ Thus, $\mathrm{H}$-bonding in the $\mathrm{HCN}$ dimer is only slightly weaker than in the water dimer, and $\mathrm{CN}^{-}$must be extensively hydrogen bonded to water. Using $D_{0\left(\mathrm{C}^{-} \mathrm{HO}\right)}=4 \mathrm{kcal} / \mathrm{mol}$ for H-bond energy in the $\left(\mathrm{NC}^{-} \cdot \cdots \mathrm{HOH}\right)$ species, we obtain $l_{\mathrm{C}^{-} \mathrm{O}}=2.94 \AA$ and $\omega_{\mathrm{e}(\mathrm{CO})}$ $=325 \mathrm{~cm}^{-1}$. This is a good compromise between the CO pair distribution function obtained in molecular dynamics simulations, that gives a first maximum near below $2.8 \AA{ }^{69}$ and the $200 \mathrm{~cm}^{-1}$ band of frequencies assigned to the center of mass vibration of the $\left(\mathrm{NC}^{-} \cdot \cdots \mathrm{HOH}\right)$ pair. $^{70}$

It is important to emphasize that ISM/scTST rate calculations do not involve the fitting of any parameters to the kinetic data. The transition-state energy is estimated from an analytical expression that only uses the parameters of the reactants and products presented in Table 2, and the experimental $\mathrm{p} K_{\mathrm{a}} \mathrm{s}$, H-bond energies and $K_{\mathrm{c}} \mathrm{s}$.
CHART 2. A-S 2 Mechanism for the Acid-Catalyzed Dedeuteration of Azulene-1-d

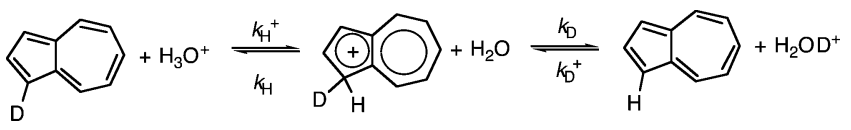

\section{Nature of the Reactants}

The best example of a virtually isothermic proton exchange involving an aromatic hydrocarbon in aqueous solution is that of azulene. The acidity of the conjugated acid of azulene ( $\left.\mathrm{p} K_{\text {azuleneH+ }}=-1.76\right)$ is very nearly identical to that of the hydronium ion $\left(\mathrm{p} K_{\mathrm{H} 3 \mathrm{O}}{ }^{+}=-1.74\right)$. Consequently the acidcatalyzed dedeuteration of azulene-1- $d$ provides an important test for the assessment of the nature of the reactants in the rates. The observed second-order rate constant for the acid catalysis is $k_{\mathrm{obs}}=0.45 \mathrm{M}^{-1} \mathrm{~s}^{-1}$ at $25^{\circ} \mathrm{C} .{ }^{12}$ The steady-state analysis of the A-S 2 mechanism in Chart 2 gives $k_{\mathrm{obs}}=k_{\mathrm{H}}{ }^{+} /\left(1+k_{\mathrm{H}} / k_{\mathrm{D}}\right)$, which, together with $k_{\mathrm{H}} / k_{\mathrm{D}}=9.2,{ }^{12}$ yields $k_{\mathrm{H}}{ }^{+}=4.6 \mathrm{M}^{-1} \mathrm{~s}^{-1}$, or $k_{\mathrm{H}}^{+}=0.77 \mathrm{M}^{-1} \mathrm{~s}^{-1}$ per acidic proton and per equivalent basic site. The $I_{P}$ of azulene is lower than that of $\mathrm{H}_{2} \mathrm{O}$; thus, we use the electronic parameters of azulene to calculate $m$. In the absence of electronic data for the radical, we use the data on the molecule $\left(I_{\mathrm{P}}=7.42 \mathrm{eV}\right.$ and $\left.E_{\mathrm{A}}=0.79 \mathrm{eV}\right)$ to obtain $m=$ 1.238. This has a small impact in the final result. For example, using the data of the phenyl radical, $I_{\mathrm{P}}=8.32 \mathrm{eV}$ and $E_{\mathrm{A}}=$ $1.096 \mathrm{eV}$, we calculate $m=1.303$. The electronic parameters of azulene with the $\mathrm{C}-\mathrm{H}$ bond parameters of benzene and the $\mathrm{O}-\mathrm{H}$ bond parameters of water, give a classical barrier of 15.6

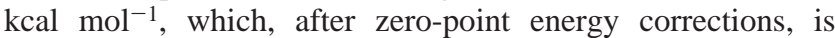
reduced to $\Delta V^{\ddagger}{ }_{\text {ad }}=13.3 \mathrm{kcal} \mathrm{mol}{ }^{-1}$. The protonation rate constant given by eq 8 is $k_{\mathrm{sc}}=0.77 \mathrm{M}^{-1} \mathrm{~s}^{-1}$, Table 3 , and includes a 4.6 tunneling correction. The coincidence with the experimental rate is just that: a coincidence. ISM cannot be expected to give better than order-of-magnitude estimates for proton-transfer rate constants in solution. However, it must also be said that our results are not biased by a convenient choice of parameters. For example, using $m=1.303$, which is representative of benzene ionization, we obtain $k_{\mathrm{sc}}=3 \mathrm{M}^{-1}$ $\mathrm{s}^{-1}$. The electronic parameter $m$ is the most sensitive parameter of ISM, and an uncertainty of $\pm 10 \%$ produces 1 order of magnitude changes in the rates. For the species addressed in this study, this uncertainty typically corresponds to $\pm 1.5 \mathrm{eV}$ in $I_{\mathrm{P}}$ or $\pm 0.5 \mathrm{eV}$ in $E_{\mathrm{A}}$. This is the level of accuracy expected for ISM/scTST calculations. ${ }^{19}$

The other extreme of virtually isothermic proton exchange in aqueous solution is the excited-state deprotonation of 5-cyano1-naphthol $(5 \mathrm{CN} 1 \mathrm{~N})$. Its excited-state acidity is $\mathrm{p} K_{\mathrm{a}} *=-2.7$, and the reciprocal of the proton dissociation time at $25{ }^{\circ} \mathrm{C}$ is $1.3 \times 10^{11} \mathrm{~s}^{-1} .{ }^{13}$ The ionization potential of the excited naphthol is reduced with respect to its ground state by the singlet-state energy, $E_{\mathrm{S}}=3.44 \mathrm{eV}$, and the excited-state ionization potential, $I_{\mathrm{P}} *=I_{\mathrm{P}}-E_{\mathrm{S}}$, must be used in eq $3 .{ }^{11}$ With the $I_{\mathrm{P}}$ and $E_{\mathrm{A}}$ of the phenoxy radical and $E_{\mathrm{S}}$ of $5 \mathrm{CN} 1 \mathrm{~N}$ we obtain $m=2.572$. Using the $\mathrm{O}-\mathrm{H}$ bond parameters of phenol and of water, together with $D_{0(\mathrm{OHO})}=2 \mathrm{kcal} / \mathrm{mol}$ and $D_{0\left(\mathrm{OHO}^{-}\right)}=4 \mathrm{kcal} / \mathrm{mol}$, we calculate a reaction frequency of $163 \mathrm{~cm}^{-1}\left(4.9 \times 10^{12} \mathrm{~s}^{-1}\right)$, a classical barrier of $3.4 \mathrm{kcal} \mathrm{mol}^{-1}$, which is reduced to 2.6 $\mathrm{kcal} \mathrm{mol}^{-1}$ after zero-point energy corrections, and the proton dissociation time given by eq 10 is $1.8 \times 10^{11} \mathrm{~s}^{-1}$ at $25^{\circ} \mathrm{C}$, Table 3. This first-order rate constant includes a tunneling correction of 2.9. According to ISM, the dramatic acid-base reactivity differences between the $\mathrm{C}-\mathrm{H}$ bond of azulene and the $\mathrm{O}-\mathrm{H}$ bond of $5 \mathrm{CN} 1 \mathrm{~N}$ are due to an increase in the electrophilicity index (a factor of $2 \times 10^{6}$ in the rate) and to 
TABLE 3: Parameters Employed in the ISM Reaction Coordinate of $\mathbf{A H}+\mathbf{B}^{-} \rightarrow \mathbf{A}^{-}+$HB Proton Transfers, and Corresponding ISM/scTST Rates ${ }^{a}$

\begin{tabular}{|c|c|c|c|c|c|c|c|}
\hline $\mathrm{AH}, \mathrm{p} K_{\mathrm{a}}$ & $\mathrm{HB}, \mathrm{p} K_{\mathrm{a}}$ & reactant Morse model & product Morse model & $m^{\mathrm{b}}$ & $D_{0(\mathrm{AHB})}$ & $k_{\mathrm{ISM}}$ & $k_{\exp }$ \\
\hline hydronium ion, -1.74 & azuleneH $\mathrm{H}^{+},-1.76$ & $\mathrm{C}_{6} \mathrm{H}_{6}$ & $\mathrm{H}_{2} \mathrm{O}$ & 1.238 & $-;-$ & 0.77 & $0.77^{c}$ \\
\hline $5 \mathrm{CN} 1 \mathrm{~N}^{*},-2.8$ & hydronium ion, -1.74 & $\mathrm{C}_{6} \mathrm{H}_{6} \mathrm{OH}$ & $\mathrm{H}_{2} \mathrm{O}$ & 2.613 & $2 ; 4$ & $1.8 \times 10^{11}$ & $1.3 \times 10^{11 d}$ \\
\hline acetic a., 4.76 & propionic a., 4.88 & $\mathrm{CH}_{3} \mathrm{COOH}$ & $\mathrm{CH}_{3} \mathrm{COOH}$ & 1.894 & $4 ; 4$ & $2.1 \times 10^{9 e}$ & $3.9 \times 10^{8 e}$ \\
\hline phenol, 9.86 & HCN, 9.0 & $\mathrm{C}_{6} \mathrm{H}_{6} \mathrm{OH}$ & $\mathrm{HCN}$ & 1.714 & $4 ; 4$ & $8.2 \times 10^{8 e}$ & $4.8 \times 10^{8 f}$ \\
\hline $\mathrm{HCN}, 9.0$ & HCN, 9.0 & $\mathrm{HCN}$ & $\mathrm{HCN}$ & 1.749 & $4 ; 4$ & $5.2 \times 10^{7 e}$ & $7 \times 10^{6 g}$ \\
\hline nitromethane, 10.22 & water, 15.74 & $\mathrm{CH}_{3} \mathrm{NO}_{2}$ & $\mathrm{H}_{2} \mathrm{O}$ & 1.095 & $-;-$ & 8.6 & $9.2^{h}$ \\
\hline acetylacetone, 9.0 & water, 15.74 & $\mathrm{CH}_{3} \mathrm{COCH}_{3}$ & $\mathrm{H}_{2} \mathrm{O}$ & 1.443 & $-;-$ & $1.5 \times 10^{4}$ & $2 \times 10^{4 i}$ \\
\hline acetic acid, 4.76 & acetone, 19.2 & $\mathrm{CH}_{3} \mathrm{COOH}$ & $\mathrm{CH}_{3} \mathrm{COCH}_{3}$ & 1.443 & $-;-$ & $3.6 \times 10^{7}$ & $6.3 \times 10^{7 j}$ \\
\hline acetone, 19.0 & pivalic acid, 5.05 & $\mathrm{CH}_{3} \mathrm{COCH}_{3}$ & $\mathrm{CH}_{3} \mathrm{COOH}$ & 1.443 & $-;-$ & $4.4 \times 10^{-8}$ & $6.8 \times 10^{-8 k}$ \\
\hline propionic acid, 4.87 & acetylacetone, 8.87 & $\mathrm{CH}_{3} \mathrm{COOH}$ & $\mathrm{CH}_{3} \mathrm{COCH}_{3}$ & 1.443 & $-;-$ & $3.4 \times 10^{5}$ & $7.3 \times 10^{4 l}$ \\
\hline acetylacetone, 8.87 & pivalic a., 5.05 & $\mathrm{CH}_{3} \mathrm{COCH}_{3}$ & $\mathrm{CH}_{3} \mathrm{COOH}$ & 1.443 & $-;-$ & 1.6 & $1.8^{k}$ \\
\hline acetic acid, 4.76 & azuleneH ${ }^{+},-1.76$ & $\mathrm{CH}_{3} \mathrm{COOH}$ & $\mathrm{C}_{6} \mathrm{H}_{6}$ & 1.238 & $-;-$ & $2.3 \times 10^{-4}$ & $3.6 \times 10^{-3 c}$ \\
\hline toluene, 41.2 & Li $c$-hexylamide, 41.6 & $\mathrm{C}_{6} \mathrm{H}_{6} \mathrm{CH}_{3}$ & $\mathrm{CH}_{3} \mathrm{NH}_{2}$ & 1 & $-;-$ & $1.2 \times 10^{-2}$ & $1.2 \times 10^{-2 m}$ \\
\hline $\mathrm{N}^{+}(\mathrm{CH} 3) \mathrm{PhCH}_{2}-\mathrm{H}$ & $\cdots{ }^{-} \mathrm{OC}\left(\mathrm{C}_{6} \mathrm{H}_{5}\right)_{2}{ }^{n}$ & $\mathrm{CH}_{3} \mathrm{NH}_{2}$ & $\mathrm{C}_{6} \mathrm{H}_{6} \mathrm{OH}$ & 1.573 & $-;-$ & $4.8 \times 10^{9}$ & $4.1 \times 10^{9 n}$ \\
\hline 2-naphthol*, 2.7 & hydronium ion, -1.74 & $\mathrm{C}_{6} \mathrm{H}_{6} \mathrm{OH}$ & $\mathrm{H}_{2} \mathrm{O}$ & 2.817 & $2 ; 4$ & $1.3 \times 10^{8}$ & $1.1 \times 10^{80}$ \\
\hline Ph-nitroethane, 7.39 & water, 15.74 & $\mathrm{CH}_{3} \mathrm{NO}_{2}$ & $\mathrm{H}_{2} \mathrm{O}$ & 1.095 & $-;-$ & $9.9 \times 10^{1}$ & $7.8^{p}$ \\
\hline$\left(\mathrm{NO}_{2}\right)_{3} \mathrm{PhCH}_{2}-\mathrm{H}$ & $\mathrm{H}-\mathrm{N}^{+} \mathrm{R}_{2}$ & $\mathrm{C}_{6} \mathrm{H}_{6} \mathrm{CH}_{3}$ & $\mathrm{CH}_{3} \mathrm{NH}_{2}$ & 1.095 & $0 ; 4$ & 9.7 & $1.4 \times 10^{1 q}$ \\
\hline mandelic acid, 22 & hydronium ion, -1.74 & $\mathrm{CH}_{3} \mathrm{COCH}_{3}$ & $\mathrm{H}_{2} \mathrm{O}$ & 1.443 & $-;-$ & $1.7 \times 10^{-5}$ & $4 \times 10^{-6 r}$ \\
\hline
\end{tabular}

${ }^{a}$ Rates at $25{ }^{\circ} \mathrm{C}$ per equivalent proton and per equivalent basic site, in $\mathrm{M}^{-1} \mathrm{~s}^{-1}$, except for italicized rates, which are in $\mathrm{s}^{-1}$; $D_{0 \text { (AHB) }}$ is in $\mathrm{kcal} / \mathrm{mol} .{ }^{b}$ The electronic models for $m$ are discussed in the text and the $I_{\mathrm{P}}$ and $E_{\mathrm{A}}$ data collected in Table 2. ${ }^{c}$ Reference 12. ${ }^{d}$ Reference $13 .{ }^{e}$ At $20{ }^{\circ} \mathrm{C}$ from ref 74, the ISM rate employed $K_{\mathrm{c}}=0.1 \mathrm{M}^{-1} .{ }^{f}$ Reference $79 .{ }^{g}$ Reference $80 .{ }^{h}$ Reference $82 .{ }^{i}$ At $12{ }^{\circ} \mathrm{C}$ from ref $2 .{ }^{j}$ Reference 85. ${ }^{k}$ Reference 86. ${ }^{l}$ At $28^{\circ} \mathrm{C}$ from ref 87. ${ }^{m}$ Reference 14. ${ }^{n}$ Reaction energy in 1,2-dichloroethane, $\Delta G^{0}=-10.2 \mathrm{kcal} / \mathrm{mol},{ }^{88}$ treated as a intramolecular reaction. ${ }^{o}$ Reference $89 .{ }^{p}$ Reference $90 .{ }^{q}$ Reaction energy in dichloromethane $\Delta G^{0} \approx-4 \mathrm{kcal} / \mathrm{mol} .{ }^{91} \quad{ }^{r}$ At $170{ }^{\circ} \mathrm{C}$ from ref 92 .

the presence of hydrogen bonding (a factor of $5 \times 10^{4}$ in the rate, including the change from a second to a first-order reaction).

Many other oxygen acids have nearly diffusion-controlled deprotonation rates in aqueous solution, even when the PT is only slightly exothermic. An example is the proton transfer from acetic acid $\left(\mathrm{p} K_{\mathrm{a}}=4.75\right)$ and propionate anion (propionic acid $\left.\mathrm{p} K_{\mathrm{a}}=4.87\right)$, which occurs with $k_{\mathrm{H}}=3.9 \times 10^{8} \mathrm{M}^{-1} \mathrm{~s}^{-1}$ at 20 ${ }^{\circ} \mathrm{C} .{ }^{74}$ This is also an example of a proton transfer from a good hydrogen-bond donor to a good hydrogen-bond acceptor, in a solvent that is both an acceptor and a donor. Under such circumstances, it is possible to have a concerted proton transfer through a hydrogen-bonded solvent molecule. ${ }^{75}$ Proton transfer with the participation of a water molecule is competitive with direct bimolecular proton transfer in the proton exchange between ammonium ion and ammonia. ${ }^{76}$ However, it was recently shown that the most stable isomer of the $\mathrm{CH}_{3}$ $\mathrm{COO}^{-}\left(\mathrm{CH}_{3} \mathrm{COOH}\right)-\left(\mathrm{H}_{2} \mathrm{O}\right)_{2}$ complex has a direct hydrogen bond between the acetate ion and acetic acid. ${ }^{77}$ Moreover, the same study showed that the energy of the isomer where a pair of acetate ions is bridged by an $\mathrm{H}_{3} \mathrm{O}^{+}$ion is $3.4 \mathrm{kcal} \mathrm{mol}^{-1}$ higher than that of the isomer with the direct $\mathrm{H}$ bond, and lies on a relatively flat surface with respect to the proton-transfer coordinate. This suggests that the difference between the direct proton transfer in $\mathrm{CH}_{3} \mathrm{COOH} /{ }^{-} \mathrm{OOCH}_{2} \mathrm{CH}_{3}$ and the waterbridged proton transfer in $\mathrm{CH}_{3} \mathrm{COOH} / \mathrm{H}_{2} \mathrm{O} /{ }^{-} \mathrm{OOCH}_{2} \mathrm{CH}_{3}$ is mostly in the shape of the barrier rather than the height of the barrier. Using the structural and electronic data of acetic acid $(m=1.894)$ and $D_{0\left(\mathrm{OHO}^{-}\right)}=4 \mathrm{kcal} / \mathrm{mol}$, we calculate $\Delta V^{\ddagger}{ }_{\mathrm{ad}}=$ $4.7 \mathrm{kcal} \mathrm{mol}^{-1}$. The rate constant, with $K_{\mathrm{c}}=0.1 \mathrm{M}^{-1}$ and $\omega_{\mathrm{e}\left(\mathrm{OO}^{-}\right)}$ $=338 \mathrm{~cm}^{-1}$, is $k_{\mathrm{sc}}=2.1 \times 10^{9} \mathrm{M}^{-1} \mathrm{~s}^{-1}$, including a 7.2 tunneling correction. For a concerted transfer through a solvent molecule, the flatness of the potential would reduce the tunneling correction and bring the calculations into better agreement with the observed rate.

Carbon acids exchange protons with oxygen bases at much slower rates that oxygen acids, as illustrated above with the azulinium ion. A remarkable exception is $\mathrm{HCN}\left(\mathrm{p} K_{\mathrm{a}}=9.0\right)$, that is known to transfer a proton very rapidly to oxygen or nitrogen bases, almost as a "normal" oxygen or nitrogen acid. ${ }^{78}$ For example, the nearly isothermic transfer to phenolate ion $\left(\mathrm{p} K_{\mathrm{a}}=9.86\right.$ for phenol) occurs with a rate of $4.8 \times 10^{8} \mathrm{~s}^{-1}$ $\mathrm{M}^{-1}$. These proton transfers are also very interesting because they occur directly between $\mathrm{HCN}$ and the bases, as opposed to the equivalent deprotonation of "normal" acids, that may proceed with the participation of one or more solvent molecules in hydroxylic solvents, ${ }^{79}$ as discussed above for carboxylic acids. We calculate the rate of proton transfer from $\mathrm{HCN}$ to the phenolate ion taking $k_{\mathrm{a}} / k_{-\mathrm{a}}=K_{\mathrm{c}}=0.1 \mathrm{M}^{-1}$ as Bednar and Jencks, using the electronic parameters associated with phenol $(m=1.714)$, the structural data for HCN and phenol, and $D_{0}$ $=4 \mathrm{kcal} / \mathrm{mol}$ for the H-bond energy. These parameters give $\Delta V^{\ddagger}{ }_{\text {ad }}=5.6 \mathrm{kcal} / \mathrm{mol}$ and $k_{\mathrm{sc}}=8.2 \times 10^{8} \mathrm{M}^{-1} \mathrm{~s}^{-1}$, including a tunneling correction of 7.4. A similar calculation for the proton exchange between $\mathrm{HCN}$ and $\mathrm{CN}^{-}$, which is also known to be direct, but using exclusively the parameters of $\mathrm{HCN}$, gives 5.2 $\times 10^{7} \mathrm{M}^{-1} \mathrm{~s}^{-1}$, and should be compared with the experimental value of $7 \times 10^{6} \mathrm{M}^{-1} \mathrm{~s}^{-1}$. ${ }^{80}$ The magnitude of the decrease in the PT rate when the base is changed from the phenolate ion to $\mathrm{CN}^{-}$is slightly underestimated probably because the same $\mathrm{H}$-bond energy was used for both cases, whereas it is more reasonable to expect that it is smaller in $\mathrm{NC}^{-} / \mathrm{HCN}$. The reactivity difference calculated with the same $\mathrm{H}$-bond energy is mostly due to the higher strength of the $\mathrm{HC}$ bond in $\mathrm{HCN}$ with respect to the $\mathrm{OH}$ bond of phenol.

Nitroalkanes are particularly strong carbon acids, but have relatively low PT rates. This has been known from early work on $\mathrm{CH}$ bond ionization, ${ }^{81}$ but Bordwell was the first to emphasize that the PT rates of nitroalkanes are more sensitive to structural change than their equilibria. ${ }^{5}$ The deprotonation rate of nitromethane $\left(\mathrm{p} K_{\mathrm{a}}=10.22, \Delta G^{0}=-7.3 \mathrm{kcal} / \mathrm{mol}\right.$ after correction for equivalent acid protons) with hydroxide ion at $25^{\circ} \mathrm{C}$ is $27.6 \mathrm{M}^{-1} \mathrm{~s}^{-1}$, whereas that of nitroethane $\left(\mathrm{p} K_{\mathrm{a}}=8.60\right.$, $\Delta G^{0}=-9.7 \mathrm{kcal} / \mathrm{mol}$ ) is $5.19 \mathrm{M}^{-1} \mathrm{~s}^{-1}$ and that of 2-nitropropane $\left(\mathrm{p} K_{\mathrm{a}}=7.74, \Delta G^{0}=-11.3 \mathrm{kcal} / \mathrm{mol}\right)$ is $0.316 \mathrm{M}^{-1} \mathrm{~s}^{-1} .82$ With the data for water and nitromethane $(m=1.095)$, we calculate $k_{\mathrm{sc}}=8.6 \mathrm{M}^{-1} \mathrm{~s}^{-1}$, which should be compared with the statistically corrected experimental rate of $9.2 \mathrm{M}^{-1} \mathrm{~s}^{-1}$ for nitromethane, Table 3 . The electron affinities of nitroethane and 2 -nitropropane are not known, but if we assume that $\alpha$-methyl substitution leads to the same changes in electron affinity as in the methane, ethane, propane series, then we should have $m=$ 


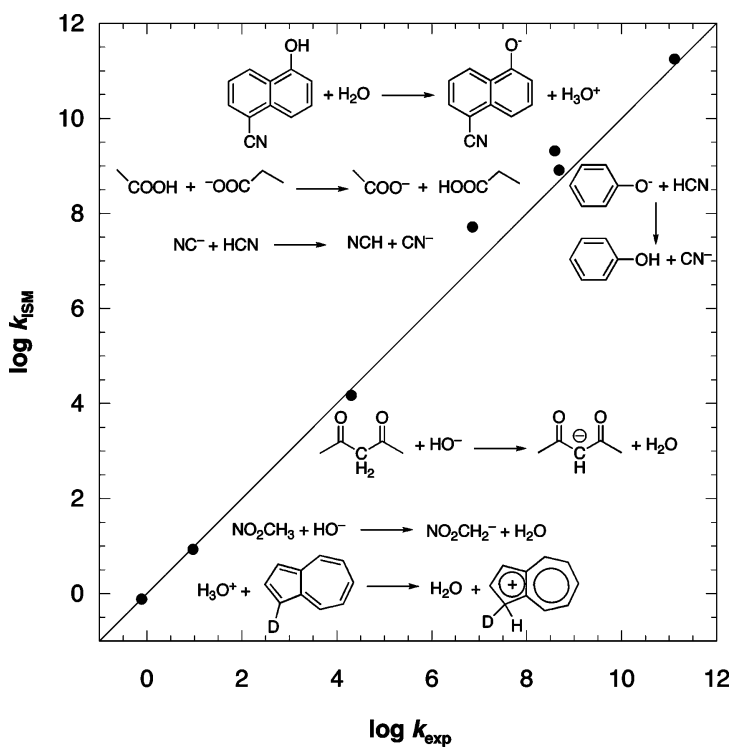

Figure 2. Correlation between calculated and statistically corrected experimental proton-transfer rates, expressed in units of $\mathrm{M}^{-1} \mathrm{~s}^{-1}$ except for the deprotonation of $5 \mathrm{CN} 1 \mathrm{~N}$, which is in $\mathrm{s}^{-1}$. The correlation coefficient is 0.997 . The line represents the ideal correlation.

1 for 2-nitropropane. With this value of $m$, the vibrationally adiabatic barrier for the 2-nitropropane $\mathrm{CH}$ bond ionization is $\Delta V_{\text {ad }}^{\ddagger}=13.1 \mathrm{kcal} / \mathrm{mol}$, higher than for nitromethane ionization, $\Delta V^{\ddagger}{ }_{\text {ad }}=12.3 \mathrm{kcal} / \mathrm{mol}$, opposing the thermodynamic trend. Thus, our calculations explain the "anomaly" observed for nitroalkane: the electronic factor dominates the thermodynamic one. This has been discussed in detail before, in the context of a simpler curve-crossing model. ${ }^{83}$

The acidity of acetylacetone, $\mathrm{CH}_{2}\left(\mathrm{COCH}_{3}\right)_{2} \mathrm{p} K_{\mathrm{a}}=9.0,{ }^{2}$ is similar to that of nitroethane, but the PT rate from the ketoform of acetylacetone to hydroxide ion, $4 \times 10^{4} \mathrm{M}^{-1} \mathrm{~s}^{-1}$ at 12 ${ }^{\circ} \mathrm{C}$, is 4 orders of magnitude higher than for nitroethane. Using the data for water and acetone $(m=1.443)$, we obtain $1.5 \times$ $10^{4} \mathrm{M}^{-1} \mathrm{~s}^{-1}$, which should be compared with the rate per acidic hydrogen of $2 \times 10^{4} \mathrm{M}^{-1} \mathrm{~s}^{-1}$. It is interesting to note that systems with higher $m$ values are less sensitive to changes in $m$ and hence less prone to anomalies.

Figure 2 shows that the absolute rate calculations are in excellent agreement with the experimental rates, although acids of widely different structures were selected for these calculations and 11 orders of magnitude are covered. ISM provides a quantitative relation between the nature of the acids and bases and their proton-transfer rates. A first impression might be that this remarkable achievement should not have been possible without explicit consideration of the solvent. In fact, as mentioned before, the solvent was implicitly involved in the reaction coordinate because we employ the experimental $\mathrm{p} K_{\mathrm{a}} \mathrm{s}$ to obtain the reaction energies, rather than the differences between bond strengths previously employed in gas-phase calculations. ${ }^{19,20}$ This is a simple and exact method to account for the thermodynamic effect of the solvent. It is also simple and accurate insofar as equilibrium solvation is maintained along the reaction coordinate, as assumed in the interpolation of $\Delta G^{0}$ from reactants to products using the reaction coordinate $n$ with eqs 5 and 6 . This approximation should only fail for ultrafast processes, where the solvent cannot accompany the rapidity of the chemical changes. The most important specific effect of the solvent is its hydrogen bonding ability, and this was also included in the reaction coordinate.

The molecular factors that dominate proton-transfer reactivity are the electrophilicity index $m$ and the H-bond strength. Low

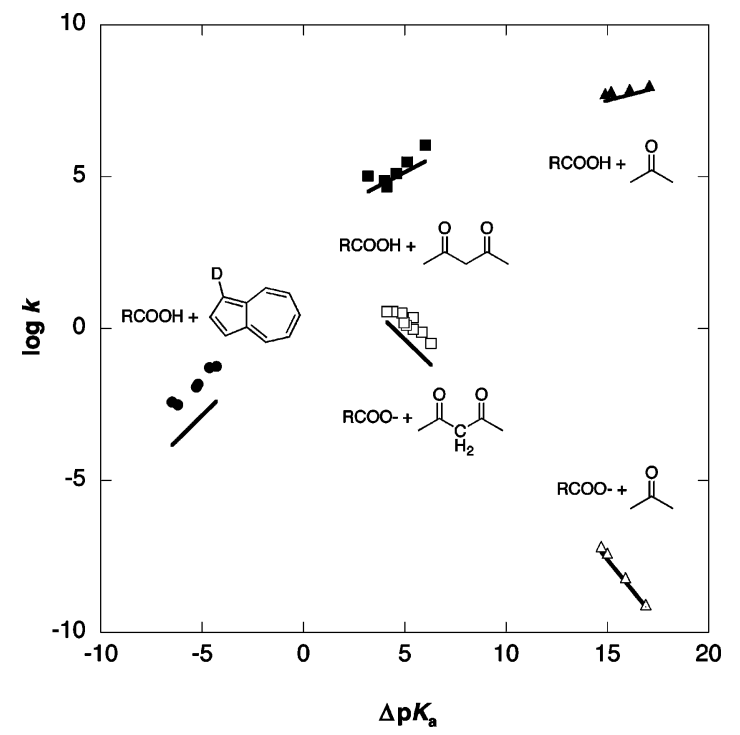

Figure 3. Brönsted plots for the carboxylic-acid-catalysis of azulene (circles), acetylacetone (closed squares), and acetone (closed triangles) and for the carboxylate-base-catalyzed enolization of acetylacetone (open squares) and acetone (open triangles). ISM/scTST rate calculations for the limiting values of each reaction series were joined by straight lines. $\Delta \mathrm{p} K_{\mathrm{a}}$ represents the statistically corrected difference between the $\mathrm{p} K_{\mathrm{a}}$ of the carbon acid and the carboxylic acid in acids catalysis, and its symmetrical in base catalysis.

values of $m(m \rightarrow 1)$ correspond to "hard molecules", 84 and lead to high barriers. Strong hydrogen bonds appreciably decrease the barriers and correspond to "normal", ${ }^{78}$ or rapidly reacting, acids. The importance of hardness and hydrogenbonding ability had been stressed before, but only the LSISM reaction coordinate gives a quantitative formulation for these molecular factors. The reaction energy and tunneling corrections also play very important roles in determining the reactivity of a given system. These effects are discussed separately below.

\section{Free-Energy Relationships}

PT reactions are at the origin of linear free-energy relationships. The most popular of them is the Brönsted relationship for acid-base catalysis ${ }^{1}$

$$
\begin{gathered}
k_{\mathrm{p}}=G_{\mathrm{p}} K_{\mathrm{a}}^{\alpha} \\
k_{-\mathrm{p}}=G_{-\mathrm{p}} K_{\mathrm{a}}^{\beta}
\end{gathered}
$$

where the constants $G_{\mathrm{p}}$ and $\alpha$ refer to the protonation of carbon bases in acid catalysis and the constants $G_{-\mathrm{p}}$ and $\beta$ refer to the deprotonation of carbon acids in base catalysis. Linear relations between the rate constants for protonation $\left(k_{\mathrm{p}}\right)$ or deprotonation $\left(k_{-\mathrm{p}}\right)$ and the acidity constant of the catalyst, have been observed when the substrate (a carbon base or a carbon acid) is held constant and the catalyst is changed within a family of structurally related acids or bases (eg., carboxylic acids or carboxylate bases). Figure 3 illustrates Brönsted relationships obtained in the carboxylic acid catalysis of azulene, ${ }^{85}$ acetylacetone, ${ }^{87}$ and acetone, ${ }^{85}$ and the carboxylate-base-catalyzed enolization of acetylacetone and acetone. ${ }^{86}$ We selected these systems to illustrate the Brönsted relationship because they cover a broad range of reaction energies and involve some of the substrates already presented. Using the parameters of those substrates, together with $\mathrm{OH}$ bond of acetic acid, we can calculate $k_{\mathrm{p}}$ and $k_{-\mathrm{p}}$ using ISM/scTST. Table 3 presents 


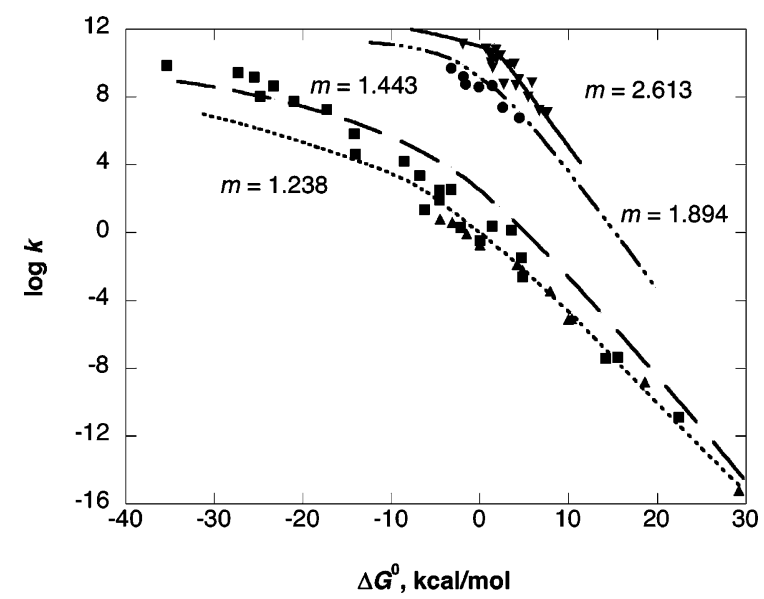

Figure 4. Free-energy relationships in the protonation of aromatic substrates (triangles), ketonization of enolates (squares), ionization of acetic acid by carboxylate bases (circles) and ESPT from aromatic alcohols (triangles). The lines represent ISM/scTST calculations with the electrophilicity index shown in the plot.

representative examples of each reaction series. The lines in Figure 3 join rate constants calculated for the most and least exothermic reactions of each series.

ISM/scTST calculations are within 1 order of magnitude of the statistically corrected experimental rates and account for the linear free-energy dependence of the rates. More specifically, the experimental and calculated Brönsted slopes for the protonation of azulene are $\alpha_{\exp }=0.61$ and $\alpha_{\text {ISM }}=0.66$, respectively, and for acetone we have $\alpha_{\exp }=0.12$ and $\beta_{\exp }=0.88$ to be compared with $\alpha_{\text {ISM }}=0.17$ and $\beta_{\text {ISM }}=0.82$. The experimental data for acetylacetone has considerable scatter, and the coefficients $\alpha_{\text {exp }}=0.43$ (correlation coefficient $R=0.84$ ) and $\beta_{\exp }$ $=0.47(R=0.91)$ have a larger uncertainty. The corresponding calculated values are $\alpha_{\text {ISM }}=0.35$ and $\beta_{\text {ISM }}=0.65$. The difference between calculated and experimental Brönsted slopes in the acid-base catalysis acetylacetone is related to the scatter of the experimental data. For example, using only the data for the PT from the keto-form of acetylacetone to the carboxylate reported by Ahrens et al., ${ }^{87}$ we obtain $\beta_{\exp }=0.60$, which is closer to the calculated value and in better agreement with the expectation from eq 11 that $\alpha+\beta=1$.

ISM calculations necessarily give $\alpha+\beta=1$ for acid and base catalysis discussed above, because they correspond to exchanging reactants and products. The slopes of the calculated free-energy curves tend to zero for very exothermic reactions and to unity for very endothermic reactions. Thus, according to ISM, the free-energy relationships are curved, rather than linear, when a wide range of free energies is involved. It is difficult to find a homogeneous series of catalysts that spans the $\mathrm{p} K_{\mathrm{a}}$ range necessary to test the anticipated curved free-energy relationships, but this difficulty can be overcome by constructing Brönsted plots where the catalyst is kept constant and the substrate is varied. Kresge and co-workers used this procedure to show that the protonation rates of aromatic substrates (benzene, azulene, methoxybenzenes, ...) by $\mathrm{H}_{3} \mathrm{O}^{+}$originated curved Brönsted plots, Figure 4. ${ }^{93}$ This figure also shows the more extensive data collected by Wirz for the ketonization of enolates. ${ }^{94}$ The distinct curvatures of these data have been rationalized in terms of quadratic free-energy relationships, such as that of Marcus. ${ }^{95,96}$ When work terms are neglected, the Marcus expression for proton transfer is usually fitted to the experimental data using two adjustable parameters: a limiting rate for very exothermic reactions, $k_{\text {diff, }}$, and a barrier for the thermoneutral reaction, $\Delta G_{0}{ }^{\ddagger}$. The free-energy dependence of the protonation of aromatic substrates and the ketonization of enolates, can be simulated by the Marcus expression when both $k_{\text {diff }}$ and $\Delta G_{0}{ }^{\ddagger}$ are fitted to the experimental rate.

Figure 4 also illustrates the free-energy dependence of a "normal" acid (the deprotonation of acetic acid by carboxylate bases), and of a family of photoacids (ESPT from aromatic alcohols to water). These acids are usually described by the Eigen mechanism, mechanism III, and are characterized by a sharp break separating the exothermic and diffusion-controlled reactions, from endothermic and thermodynamically controlled ones. These free-energy relationships are not quadratic, and have been described as changing from $\alpha=0$ (or $\beta=1$ ) to $\alpha=1$ (or $\beta=0$ ) when $\Delta G^{0}$ changes sign.

Rather than fitting functional forms to reproduce the observed free-energy relationships, we can employ ISM/scTST to make absolute rate calculations for these series of reactions, using the parameters already discussed for azulene, acetone, acetic acid, 5CN1N and water. The lines presented in Figure 4 guide the eye for ISM/scTST calculations sharing the same set of parameters except $\Delta G^{0}$. They cover 26 orders of magnitude in the rates and are in excellent agreement with the experimental data. Values of $m$ close to unity lead to high barriers and approximately linear free-energy relationship, whereas large values of $m$ reduce the PT barrier and originate Eigen plots. The quadratic free-energy relationships associated with the Marcus equation are only apparent for intermediate values of $m$. These calculations do not include the effect of diffusion and do not involve any adjustable parameters. The sharp break in the free-energy relations of oxygen acids results from the low barrier due to large values of $m$ and significant H-bonding.

The free-energy relationships predicted by ISM are not quadratic. Quadratic dependencies lead to "inverted regions" (a decrease in the rate with an increase in exothermicity), which do not have a correspondence in potential energy surfaces for adiabatic reactions. The limiting values of ISM for exothermic atom or proton transfers are barrierless reactions. As this limit is approached, diffusion or solvent reorientation, may become the rate-determining step. For example, at $\Delta G^{0}=-0.6 \mathrm{kcal} /$ mol the deprotonation times of cyanonaphthols in water reach the Debye relaxation time of water, 8 ps. More importantly, according to eqs $1-2$ as the endothermicity increases, $n_{\mathrm{HB}} \rightarrow 1$ and $n_{\mathrm{HA}} \rightarrow 0$, which implies that $l_{\mathrm{HA}}{ }^{\ddagger}-l_{\mathrm{HA} \text {,eq }}$ tends to infinity and $l_{\mathrm{HB}}{ }^{\ddagger}-l_{\mathrm{HB}, \text { eq }}$ tends to zero. This requires that the sum of bond extensions, $\left|l_{\mathrm{HA}}{ }^{\ddagger}-l_{\mathrm{HA}, \mathrm{eq}}\right|+\left|l_{\mathrm{HB}}{ }^{\neq}-l_{\mathrm{HB}, \mathrm{eq}}\right|$, increases with $\left|\Delta G^{0}\right|$ and that the intrinsic barrier also increases with $\left|\Delta G^{0}\right|$. To the best of our knowledge, the first argument that intrinsic barriers should increase with $\left|\Delta G^{0}\right|$ was made by Koepple and Kresge. ${ }^{97}$ It was given a quantitative basis in the original formulation of ISM, ${ }^{15,98}$ which was closely followed by an empirical deduction based on hydroxide ion catalyzed deprotonations, ${ }^{99}$ and an $a b$ initio study on $\mathrm{H}$ atom transfers. ${ }^{100}$

\section{Primary Kinetic Isotope Effects}

Westheimer indicated that the zero-point energy difference between $\mathrm{CH}$ and $\mathrm{CD}$ bonds should be fully operational for symmetric PT reactions, because they correspond to transition states with a symmetrical stretching vibration that is independent of the mass of the central atom. ${ }^{3}$ Thus, at $298 \mathrm{~K}$, symmetrical PT between carbon atoms should attain the maximum KIE of $k_{\mathrm{H}} / k_{\mathrm{D}}=6.2$, and between oxygen atoms this maximum should reach 7.9. Shortly after, Bell pointed out that Westheimer ignored the bending vibrations and the effect of the curvature of the potential energy surface at the transition state. ${ }^{101} \mathrm{He}$ further suggested that tunneling could compensate for the 


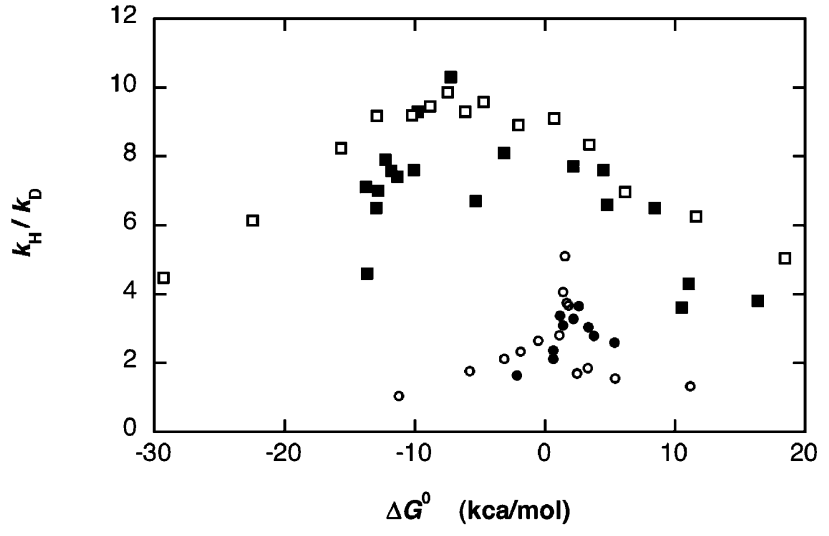

Figure 5. Kinetic isotope effects in the ionization of nitroalkanes to water, hydroxide and carboxylate ions (squares), and in the ESPT of naphthols to water (circles). ISM/scTST calculations (open symbols) employed the data for nitromethane or excited naphthols and water.

expected decrease in KIE when such effects are taken into consideration. Quantum mechanical theories, including tunneling and proton vibrational levels, have also been formulated and applied to the interpretation of the free-energy dependence of KIE. Such theories also predicted a maximum KIE for symmetrical PT. ${ }^{102,103}$

Early experimental evidence that KIE go through a maximum near $\Delta G^{0}=0$ was presented by Kresge and Bell. ${ }^{82,104-106}$ Figure 5 presents KIE for the ionizations of nitroalkanes with bases such as $\mathrm{H}_{2} \mathrm{O}, \mathrm{OH}^{-}, \mathrm{RCOO}^{-}$, or $\mathrm{PhO}^{-90,106-108}$ and of excited naphthols in water. ${ }^{11,109}$ These systems were selected to ensure a high degree of homogeneity in the reaction series. For the nitroalkanes, the KIE maximum is shifted toward the weakest bond, as expected, but for the naphthols, the opposite is observed. This unbalance is due to the presence of a stronger H-bond in the products of the naphthol ionizations. Additionally, the maximum KIE is higher than expected from zero-point energy changes for the nitroalkanes, $k_{\mathrm{H}} / k_{\mathrm{D}}=8.1$, but the opposite is observed for naphthols, $k_{\mathrm{H}} / k_{\mathrm{D}} \approx 3.5$.

Figure 5 also illustrates KIE calculated by ISM/scTST. The vibrational frequencies respond to the isotopic substitution and strongly modulate the vibrationally adiabatic path used for the tunneling corrections. For that reason, ISM/scTST calculations for proton and deuteron transfers were made for different reaction energies and the ratio of those rates is represented in Figure 5, point by point. The asymmetry in the reaction path produces an asymmetry in the tunneling corrections that is reflected in the KIE.

\section{Solvent Effects}

Changing solvents may affect the PT rates in at least three different ways: (i) the acidity constants change with the solvent, and this is reflected in the PT rates through their free-energy dependence; (ii) the H-bond energies increase with a decrease in the solvent polarity and a H-bonded intermediate (or an ion pair) may be formed in weakly polar solvents; (iii) the electrophilicity index $m$ may also change with the solvent polarity and heighten the electronic effects. An immense variety of situations result from the combination of these factors with the change in the nature of the reactants. In this work, we will focus only in weakly polar solvents because they lead to ion pairs and display the most extreme solvent effects.

Streitwieser and co-workers studied in detail the mechanism of proton exchange between aromatic hydrocarbons and lithium or cesium cyclohexylamide in cyclohexylamine. The exchange between toluene- $\alpha-d$ and lithium cyclohexylamide $\left(\mathrm{LiNHC}_{6} \mathrm{H}_{11}\right)$

$$
\begin{aligned}
& \mathrm{C}_{6} \mathrm{H}_{5} \mathrm{CH}_{2} \mathrm{D}+\mathrm{C}_{6} \mathrm{H}_{11} \mathrm{NH}^{-} \mathrm{Li}^{+} \longrightarrow \mathrm{C}_{6} \mathrm{H}_{5} \mathrm{CH}_{2}{ }^{-} \mathrm{Li}^{+}+ \\
& \mathrm{C}_{6} \mathrm{H}_{11} \mathrm{NHD}
\end{aligned}
$$

is particularly interesting because the statistically corrected acidity constants are similar, $\mathrm{p} K_{\text {toluene }}=41.2$ and $\mathrm{p} K_{\mathrm{CsCHA}}=$ 41.6. ${ }^{110}$ and the reaction is virtually isoenergetic. The deuterium exchange rate is $5.7 \times 10^{-3} \mathrm{M}^{-1} \mathrm{~s}^{-1}$ at $25^{\circ} \mathrm{C}$, and increases to $1.9 \times 10^{-2} \mathrm{M}^{-1} \mathrm{~s}^{-1}$ at $50{ }^{\circ} \mathrm{C} .{ }^{111}$ At the lower temperature the KIE for the exchange of deuterium relative to tritium is $k_{\mathrm{D}} / k_{\mathrm{T}}$ $=2.82$, and relative to the proton it is $k_{\mathrm{H}} / k_{\mathrm{D}}=11 .{ }^{14} \mathrm{With} m=$ 1 , our reference for hydrogen and $\mathrm{sp}^{3}$ carbon atoms in hydrocarbons, ${ }^{19}$ we calculate a deuterium exchange rate of 1.5 $\times 10^{-3} \mathrm{M}^{-1} \mathrm{~s}^{-1}$ at $25^{\circ} \mathrm{C}$ and $1.2 \times 10^{-2} \mathrm{M}^{-1} \mathrm{~s}^{-1}$ at $50^{\circ} \mathrm{C}$. The proton exchange is reported in Table 3 and is yet another case of coincidence between calculated and experimental values. Furthermore, at $25{ }^{\circ} \mathrm{C}$ we obtain $k_{\mathrm{D}} / k_{\mathrm{T}}=2.4$ and $k_{\mathrm{H}} / k_{\mathrm{D}}=7.9$.

The PT rates in the contact radical-ion pairs (CRIP) formed in 1,2-dichloroethane between benzophenone- $N, N$-dimethylaniline and 4-dimethoxybenzophenone $-N, N$-dimethylaniline are $4.1 \times 10^{9}$ and $2.1 \times 10^{9} \mathrm{~s}^{-1}$, whereas the respective freeenergies are $\Delta G^{0}=-10.2$ and $-14.1 \mathrm{kcal} / \mathrm{mol} .{ }^{112}$ This has been interpreted as an example of an "inverted region", 6,7,88 and it was rationalized in terms of a nonadiabatic model. However, this "inverted region" is much less pronounced than the "nitroalkane anomaly", where the PT rate decreases by a factor of 100 for the same decrease in $\Delta G^{0}$. We showed above that such "anomalies" are likely to be due to a change in $m$ within the reaction series. This electronic effect can be assessed using the reduction potentials $\left(E_{1 / 2}\right)$ of $4,4^{\prime}$-substituted benzophenones reported by Peters, ${ }^{112}$ and their expected correlation with the electron affinities

$$
E_{1 / 2}=E_{\mathrm{A}}-\left[\Delta G_{\mathrm{solv}}\left(\mathrm{A}^{-}\right)-\Delta G_{\mathrm{solv}}(\mathrm{A})\right]+\text { constant }
$$

where $\Delta G_{\text {solv }}$ represent the solvation free-energies of the anion $\left(\mathrm{A}^{-}\right)$and neutral molecule $(\mathrm{A})$. Assuming that $\left[\Delta G_{\text {solv }}\left(\mathrm{A}^{-}\right)^{-}\right.$ $\left.\Delta G_{\text {solv }}(\mathrm{A})\right]$ does not change for different $\mathrm{A}$, the expression above leads to $\Delta E_{\mathrm{A}}=\Delta E_{1 / 2},{ }^{113,114}$ and from the variation of $E_{1 / 2}$ in the series of substituted benzophenones, we can obtain the variation of $E_{\mathrm{A}}$. We calculate the PT barriers in CRIPs with the Morse data for phenol representing the $\mathrm{OH}$ bond in the benzophenone ketyl radical, with the Morse data of methylamine representing the $\mathrm{CH}$ bond in the $N, N$-dimethylaniline radical cation. The values of $E_{\mathrm{A}}$ along the series of substituted benzophenones can be estimated from the variation in $E_{1 / 2}$ relative to $4,4^{\prime}$-dichlorobenzophenone. The absolute PT rates within the ion pairs can only be calculated if the promoting mode frequency of this first-order reaction is known. Peters and Kim employed values between $200 \mathrm{~cm}^{-1}\left(6.0 \times 10^{12} \mathrm{~s}^{-1}\right)$ and $150 \mathrm{~cm}^{-1}\left(4.5 \times 10^{12} \mathrm{~s}^{-1}\right) .88$ In Figure 6 we show that our calculations using a pre-exponential factor of $5 \times 10^{12} \mathrm{~s}^{-1}$ are within a factor of 5 of the experimental rates and closely follow the free-energy relationship observed in acetonitrile.

The "inverted region" is only observed in weakly polar solvents, such as 1,2-dichloroethane. It is beyond the scope of this work to present a full quantitative account of solvent effects in PT, but an educated guess of such effects can be based on the variation of $\Delta G_{\text {solv }}$ with the polarity of the solvent. Since the solvation of $\mathrm{A}^{-}$is more exothermic than that of $\mathrm{A}$, we have $\left[\Delta G_{\text {solv }}\left(\mathrm{A}^{-}\right)-\Delta G_{\text {solv }}(\mathrm{A})\right]<0$ for polar solvents, but this term 


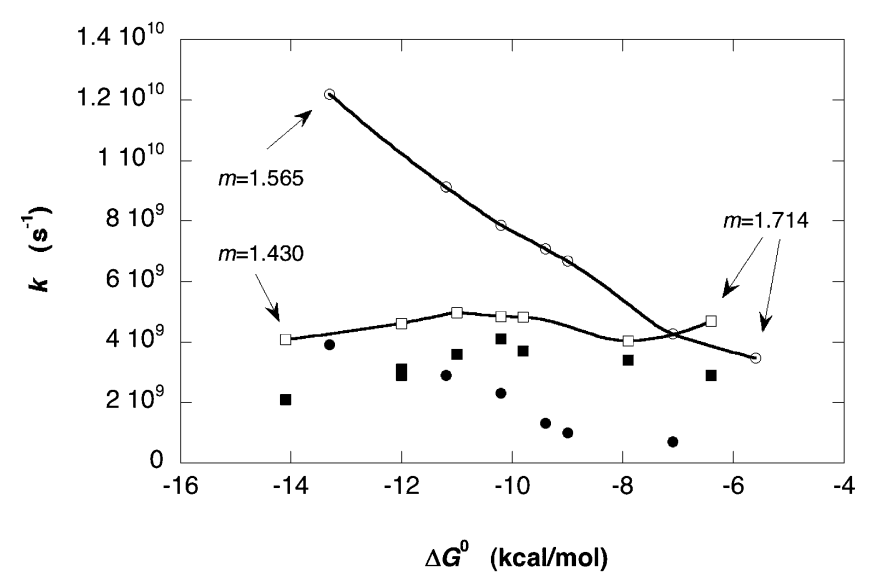

Figure 6. Free-energy relationships observed in CRIP in acetonitrile (circles) and 1,2-dichloroethane (squares). ISM/scTST calculations (open symbols and lines) were made with variable $m$, estimated from $\Delta E_{\mathrm{A}}=\Delta E_{1 / 2}$ for acetonitrile and $\Delta E_{\mathrm{A}}=2 \Delta E_{1 / 2}$ for 1,2-dichloroethane.

will approach zero for less polar solvents. Thus, $E_{\mathrm{A}}$, and $m$, will tend to be larger in less polar solvents and, for the same $\Delta G^{0}$, the rates should be higher. This tendency is observed for the least exothermic reactions of Figure 6. The decrease in PT rate in 1,2-dichloroethane observed for the most exothermic systems, involving benzophenones with more negative $E_{1 / 2}$ values, can be explained by the higher sensitivity of $E_{\mathrm{A}}$ in this solvent. Figure 6 shows that the electronic effects dominate the thermodynamic ones when $\Delta E_{\mathrm{A}}=2 \Delta E_{1 / 2}$.

PT in CRIP is not an example of nonadiabatic PT because this thermal reaction occurs adiabatically on the lowest potential energy surface. However, nonadiabatic PTs may actually exist. A likely candidate is the photohydration of styrenes. ${ }^{115,116}$ Thermodynamical and kinetic requirements impose that the reactants are in the excited singlet state and the products are formed in the ground state. According to the definition of Förster, ${ }^{117}$ this is a nonadiabatic PT, and intersecting-state formulations are more appropriate to treat these systems. ${ }^{118,119}$

\section{Temperature Dependencies}

A final test to validate our PT rate calculations is the comparison between the calculated and experimental temperature dependencies of the rates. One of the fastest intermolecular PT is the proton dissociation of electronically excited 5-cyano1 -napthol in water $\left(\mathrm{p} K_{\mathrm{a}}=-2.72\right)$. The proton dissociation times for temperatures above $25{ }^{\circ} \mathrm{C}$ approach the Debye relaxation times of water. ${ }^{13}$ ISM/scTST calculations using the data for phenol and water in Table 2, together with the electronic energy of 5-cyano-1-napthol, required to calculate $m=2.613$ with $I_{\mathrm{P}} *$ $=I_{\mathrm{P}}-E_{\mathrm{S}}$, give first-order proton-dissociation rates in very good agreement with the experimental data, Figure 7. A similar agreement was found in the temperature dependence of the firstorder proton-dissociation rates of 2-napthol. The latter calculation employed the dynamic $\mathrm{p} K_{\mathrm{a}}$ at each temperature. ${ }^{89}$

We have seen before that nitroalkanes have particularly slow PT rates. The deprotonation rate of 1-phenyl-1-nitroethane and its 1- $d$ analogue by $\mathrm{OH}^{-}$in water were measured in the $5-45$ ${ }^{\circ} \mathrm{C}$ temperature range, ${ }^{90}$ and can be calculated with its $\mathrm{p} K_{\mathrm{a}}$ at $25^{\circ} \mathrm{C}, 7.39,{ }^{108}$ and the data for nitromethane and water. Figure 7 shows that the experimental rates are slightly overestimated and the barriers slightly underestimated (experimental enthalpy of activation $\Delta H^{\ddagger}=12.3 \mathrm{kcal} / \mathrm{mol}$ vs vibrationally adiabatic barrier $\Delta V_{\mathrm{ad}}{ }^{\ddagger}=10.9 \mathrm{kcal} / \mathrm{mol}$ ), which is not unexpected because the real value of $m$ should be lower than that of nitromethane, as discussed before for nitroethane. The calculated KIE de-

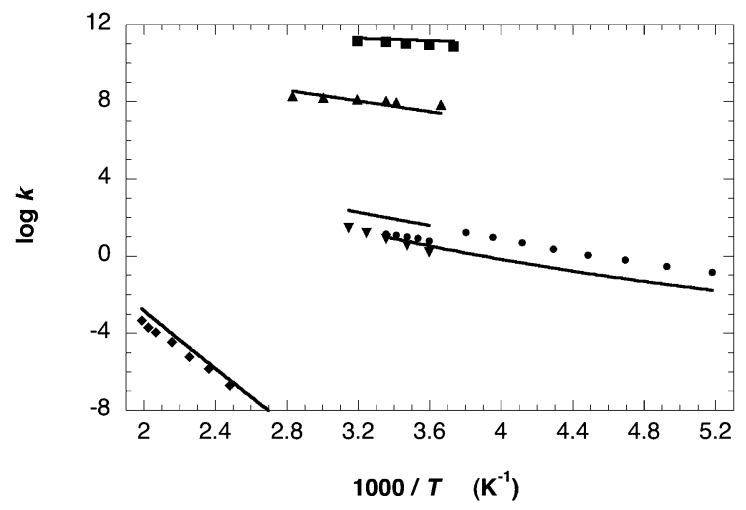

Figure 7. Effect of the temperature on the first-order rate constants in water for the uncatalyzed exchange of deuterium into the $\alpha$-position of $(R)$-mandelate (lozenges), ESPT of 2-naphthol (triangles), and 5-cyano-1-naphthol (squares), and on the second-order deprotonation rate constant of 1-phenyl-1-nitroethane by $\mathrm{OH}^{-}$(triangles). The circles represent the deprotonation of trinitrotoluene by DBU in dichloromethane.

creases from 12 at $5{ }^{\circ} \mathrm{C}$ to 7 at $45^{\circ} \mathrm{C}$, whereas the experimental KIE decreases from 9.2 to 5.8 .

Aqueous solutions impose a relatively high temperature as the lower limit for the temperature dependence studies of intermolecular PT. This can be overcome with organic solvents. A very interesting system studied in dichloromethane down to $-80{ }^{\circ} \mathrm{C}$ is the deprotonation of trinitrotoluene by 1,8 -diazabicyclo[5.4.0]undec-7-ene (DBU) in dichloromethane, that leads to an ion pair. ${ }^{91,120}$ The equilibrium constant for the formation of the ion pair gives a reaction energy $\Delta G^{0} \approx-2 \mathrm{kcal} / \mathrm{mol}$ in dichloromethane. ${ }^{91}$ In terms of our reaction coordinate, the ion pair can be regarded as a $\mathrm{H}$-bond of a significant energy because it involves oppositely charged species in dichloromethane. The calculations illustrated in Figure 7 employed the Morse parameters of toluene and methylamine ( $\mathrm{NH}$ bond), together with $\Delta G^{0}$ $\approx-2 \mathrm{kcal} / \mathrm{mol}$ and a $4 \mathrm{kcal} / \mathrm{mol} \mathrm{H}$-bond energy for the ion pair only. In the absence of information on the $I_{\mathrm{P}}$ and $E_{\mathrm{A}}$ of the reactants involved, we employed the electrophilicity index of nitromethane, $m=1.095$. This is a reasonable approximation because the electron affinities are not expected to be very high and, consequently, $m$ cannot be much greater than unity. The interest of this system is not just the extended temperature dependence experimentally studied, and very well reproduced by the calculations. Its interest also comes from the curvature of the Arrhenius plot and from the large KIE, that increase to 27 at $-10{ }^{\circ} \mathrm{C}$ and to 50 at $-40{ }^{\circ} \mathrm{C}$ and indicate very large tunneling effects. Our semiclassical tunneling correction is 21 at $25^{\circ} \mathrm{C}$, increases to 215 at $-40{ }^{\circ} \mathrm{C}$, and reaches 4600 at -80 ${ }^{\circ} \mathrm{C}$. Only such extreme tunneling corrections give the curvature experimentally observed in the Arrhenius plot. Moreover, the calculated KIE increases from 11 at $25^{\circ} \mathrm{C}$, to 19 at $-10^{\circ} \mathrm{C}$, and 39 at $-40{ }^{\circ} \mathrm{C}$, in good agreement with the experimental data. The importance of tunneling in this system comes from the formation of the ion pair. Figure 8 illustrates the reaction coordinate for this system. The products side is much steeper, as the ion pair is taken as a hydrogen bond worth $4 \mathrm{kcal} / \mathrm{mol}$, and leads to an increase in the tunneling correction. In a more polar solvent, such as acetonitrile, a looser ion pair is formed and the reaction coordinate in the products is not as steep. In such cases the tunneling is not expected to be as high, and the KIE is smaller, as observed experimentally. ${ }^{91}$

A remarkable example of a very slow PT studied in aqueous solution is the racemization of $(R)$-mandelate and exchange of its $\alpha$-hydrogen with deuterium. Much of the interest in this reaction comes from the fact that $(R)$-mandelate is the natural 


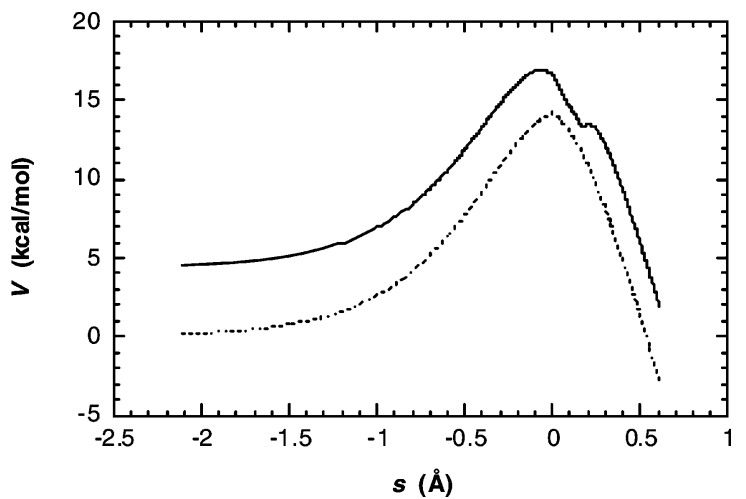

Figure 8. Classical (dotted line) and vibrationally adiabatic (full line) paths of LS-ISM/scTST for the deprotonation of trinitrotoluene by 1,8-diazabicyclo[5.4.0] undec-7-ene (DBU) in dichloromethane. The experimental $\Delta G^{0} \approx-1.9 \mathrm{kcal} / \mathrm{mol}$ was imposed on this path and the ion pair was modeled as $4 \mathrm{kcal} / \mathrm{mol} \mathrm{H}$-bond strength. The Morse parameters of toluene and methylamine (NH bond) were employed as models for the reactant and product bonds, respectively, together with $m=1.095$.

substrate of mandelate racemase, that catalyzes its racemization with a turnover number of $k_{\text {cat }}=480 \mathrm{~s}^{-1}$ at $25^{\circ} \mathrm{C}$. ${ }^{121} \mathrm{In}$ view of the slowness of the uncatalysed exchange with deuterium at $\mathrm{pD} 7.5$, the effect of temperature on the first-order rate constant was determined at temperatures between 130 and $190{ }^{\circ} \mathrm{C} .{ }^{92}$ The experimental rates of the uncatalyzed exchange are compared in Figure 7 with the rates calculated using the acidity constant of mandelic acid ionizing as a carbon acid, $\mathrm{p} K_{\mathrm{a}}{ }^{\mathrm{K}}=22,{ }^{122,123}$ and the data for acetone and water. The experimental $\Delta H^{\ddagger}=$ $31 \mathrm{kcal} / \mathrm{mol}$, is in very good agreement with the calculated barrier $\Delta V^{\ddagger}{ }_{\text {ad }}=31.7 \mathrm{kcal} / \mathrm{mol}$. This high barrier derives from the endothermicity of the formation of the enolate ion intermediate, because the acidity constants for the ionization of mandelic acidic as a carbon acid, 22.0, and as an oxygen acid, 3.41 , require that the enolate ion is $25.3 \mathrm{kcal} / \mathrm{mol}$ above the mandelate ion in aqueous solution. ${ }^{92}$ Extrapolated to $25^{\circ} \mathrm{C}$, the calculated and experimental rates are $1 \times 10^{-13}$ and $3 \times 10^{-13}$ $\mathrm{s}^{-1}$, respectively.

\section{Conclusions}

The calculation of PT rates using ISM/scTST depends exclusively on the following parameters of reactants and products: the masses of the atoms, the bond lengths, vibration frequencies, and bond dissociation energies of the reactive bonds, the ionization potential and electronic affinity of the radicals, the acidity constants and the H-bond energies. The simple and fast calculations afforded by this method are nevertheless very accurate. The correlation between the experimental and ISM/scTST absolute rates of the prototypical systems collected in Table 3 has a coefficient of 0.996. This cannot be assigned to any tailoring of the method to specific systems, as illustrated by the large diversity of atom and proton-transfer treated by ISM/scTST, or to a compensation of errors, as shown by the quantitative treatment of temperature and KIE effects. The simplicity of the method favors the understanding of how each property of the reactants or products influences the rate of a PT reaction. ISM links the solution of one system to those of related systems. The method highlights the role of electronic indexes, such as the Parr's electrophilicity index, in the making of intrinsic barriers, and provides a rational for empirical freeenergy relationships, such as the Brönsted relation and Marcus's quadratic relation, and for the conditions for which they fail.

The order-of-magnitude agreement between the absolute rate calculations and the experimental data in solution is quite reassuring, but perhaps the greatest value of the method is to provide a clear relation between the properties of the reactants and products and those of transition states in atom and proton transfers. In particular, it is shown that an increase in electron affinity of the acid/base significantly lowers the PT barrier. Hydrogen bonding can also lower the PT barrier and, most interestingly, may lead to thinner barrier and enhanced tunneling. Tunneling corrections along the vibrationally adiabatic reaction path are present in all our calculations. At room temperature they usually range from 2 to 15 . The most dramatic tunneling corrections result from the thin barriers obtained when the end atoms are close together, due to H-bonding, especially when the barriers remain high.

Today, chemists have an arsenal of theoretical methods to attack problems of molecular structure and reactivity. ISM is an addition to this arsenal that aims at the rationalization of apparently unrelated properties and processes, and complements the more sophisticated methods already available. In view of its simplicity and insight, ISM may be the first choice for a theoretical treatment before going into the detailed treatment of a given proton transfer. However, issues such as solvent dynamics or multidimensional effects can only be tackled with more sophisticated, and time-consuming, methods. ${ }^{60,124-126}$

Acknowledgment. We thank Fundação para a Ciência e Tecnologia (Portugal) and FEDER for financial support of Project No. POCTI/QUI/47267/2002. M.B. expresses thanks for the financial support by FCT through Grant BPD/22070/2005.

Supporting Information Available: Text giving the algorithm for LS-ISM/scTST calculations and text and tables detailing the input and output of the calculations on all the systems of Table 3. This material is available free of charge via the Internet at http://pubs.acs.org.

\section{References and Notes}

(1) Brönsted, J. N.; Pedersen, K. L. Z. Phys. Chem. 1924, 108, 185.

(2) Eigen, M. Angew. Chem., Int. Ed. Engl. 1964, 3, 1.

(3) Westheimer, F. H. Chem. Rev. 1961, 61, 265.

(4) Swain, C. G.; Stivers, E. C.; Reuwer, J. F.; Schaad, L. J. J. Am. Chem. Soc. 1958, 80, 5885.

(5) Bordwell, F. G.; Boyle, W. J., Jr.; Hautala, J. A.; Yee, K. C. J. Am. Chem. Soc. 1969, 91, 4002.

(6) Peters, K. S.; Cashin, A.; Timbers, P. J. Am. Chem. Soc. 2000, $122,107$.

(7) Andrieux, C. P.; Gamby, J.; Hapiot, P.; Saveant, J. M. J. Am. Chem. Soc. 2003, 125, 10119.

(8) Pines, E.; Magnes, B. Z.; Lang, M. J.; Fleming, G. R. Chem. Phys. Lett. 1997, 281, 413 .

(9) Huppert, D.; Tolbert, L. M.; Linares-Samaniego, S. J. Phys. Chem. A 1997, 101, 4602.

(10) Hirchi, J.; Singleton, D. A. J. Am. Chem. Soc. 2005, 127, 3294

(11) Barroso, M.; Arnaut, L.; Formosinho, S. J. J. Photochem. Photobiol. A: Chem 2002, 154, 13

(12) Gruen, L. C.; Long, F. A. J. Am. Chem. Soc. 1967, 89, 1287.

(13) Pines, E.; Pines, D.; Barak, T.; Magnes, B.-Z.; Tolbert, L. M.; Haubrich, J. E. Ber. Bunsen-Ges. Phys. Chem. 1998, 102, 511.

(14) Streitwieser, A., Jr.; Owens, P. H.; Sonnischsen, G.; Smith, W. K.; Ziegler, G. R.; Niemeyer, H. M.; Kruger, T. L. J. Am. Chem. Soc. 1973, 95, 4254.

(15) Varandas, A. J. C.; Formosinho, S. J. J. Chem. Soc. Faraday Trans. 2 1986, 82, 953.

(16) Formosinho, S. J. Understanding Chemical Reactivity Through the Intersecting-State Model. In Theoretical and Computational Models for Organic Chemistry; Formosinho, S. J., Csizmadia, I. G., Arnaut, L. G., Eds.; NATO ASI; Kluwer: Dordrecht, The Netherlands, 1991; pp 159.

(17) Pais, A. A. C. C.; Arnaut, L. G.; Formosinho, S. J. J. Chem. Soc., Perkin Trans. 2 1998, 2577.

(18) Arnaut, L. G.; Pais, A. A. C. C.; Formosinho, S. J. J. Mol. Struct. 2001, 563/564, 1.

(19) Arnaut, L. G.; Pais, A. A. C. C.; Formosinho, S. J.; Barroso, M. J. Am. Chem. Soc. 2003, 125, 5236. 
(20) Barroso, M.; Arnaut, L. G.; Formosinho, S. J. Chem. Phys. Chem. $\mathbf{2 0 0 5}, 6,363$.

(21) Johnston, H. S.; Parr, C. J. Am. Chem. Soc. 1963, 85, 2544.

(22) Pauling, L. J. Am. Chem. Soc. 1947, 69, 542.

(23) Varandas, A. J. C.; Brown, F. B.; Mead, C. A.; Truhlar, D. G.; Garrett, B. C. J. Chem. Phys. 1987, 86, 6258.

(24) Parr, R. G.; Szentpály, L. v.; Liu, S. J. Am. Chem. Soc. 1999, 121, 1922.

(25) Arnaut, L. G.; Formosinho, S. J.; Burrows, H. D. Chemical Kinetics; Elsevier: Amsterdam, 2007.

(26) Truhlar, D. G. J. Am. Chem. Soc. 1972, 94, 7584

(27) Agmon, N.; Levine, R. D. J. Chem. Phys. 1979, 71, 3034.

(28) Marcus, R. A. J. Phys. Chem. A 1997, 101, 4072.

(29) Wilson, E. B., Jr. J. Chem. Phys. 1939, 7, 1047.

(30) The Supporting Information presents the complete algorithm for the intersecting/interacting state model.

(31) Bell, R. P. The Tunnel Effect in Chemistry; Chapman \& Hall: London, 1980.

(32) Hibbert, F. Adv. Phys. Org. Chem. 1986, 22, 113

(33) Lippincott, E. R.; Schroeder, R. J. Chem. Phys. 1955, 23, 1099.

(34) Weiss, J. J. J. Chem. Phys. 1964, 41, 1120.

(35) Walrafen, G. E.; Fisher, M. R.; Hokmabadi, M. S.; Yang, W.-H. J. Chem. Phys. 1986, 85, 6970 .

(36) Glasstone, S.; Laidler, K. J.; Eyring, H. The Theory of Rate Processes; McGraw-Hill: New York, 1941.

(37) Stahl, N.; Jencks, W. P. J. Am. Chem. Soc. 1986, 108, 4196.

(38) Scott, R. L. J. Phys. Chem. 1971, 75, 3843.

(39) Tolbert, L. M.; Solntsev, K. M. Acc. Chem. Res. 2002, 35, 19.

(40) Bell, R. P. Acid-Base Catalysis; Oxford University Press: Oxford,

U.K., 1941.

(41) Carey, D. M.; Korenowski, G. M. J. Chem. Phys. 1998, 108, 2669.

(42) Triolo, R.; Narten, A. H. J. Chem. Phys. 1975, 63, 3624. 6618 .

(43) Meot-Ner (Mautner), M.; Speller, C. V. J. Phys. Chem. 1986, 90 ,

(44) Salvador, P.; Duran, M.; Dannenberg, J. J. J. Phys. Chem. A 2002, 106,6883

(45) Xie, Y.; Schaefer, H. F., III. J. Chem. Phys. 1993, 98, 8829

(46) Cooper, P. D.; Kjaergaard, H. G.; Langford, V. S.; McKinley, A.

J.; Quickenden, T. I.; Schofield, D. P. J. Am. Chem. Soc. 2003, 125, 6048.

(47) Dunn, M. E.; Pokon, E. K.; Shields, G. C. J. Am. Chem. Soc. 2004,

126,2647

(48) Novak, A. Struct. Bonding (Berlin) 1974, 18, 177.

(49) Henry, M. Chem. Phys. Chem. 2002, 3, 561.

(50) Bakó, I.; Pálinkás, G. J. Mol. Struct. 2002, 594, 179.

(51) Bizzarri, A.; Stolte, S.; Reuss, J.; van Duijneveldt- van de Rijdt, J.

G. C. M.; van Duijneveldt, F. B. Chem. Phys. 1990, 143, 423.

(52) Derissen, J. L. J. Mol. Struct. 1971, 7, 67.

(53) Lofgren, S. M.; Mahling, P. R.; Togeas, J. B. J. Phys. Chem. A 2005, 109, 5430.

(54) Samson, C. C. M.; Klopper, W. J. Mol. Struct. (THEOCHEM) 2002, $586,201$.

(55) van Koningsveld, H.; Venema, F. R. Acta Crystallogr. Sect. C 1991 $47,289$.

(56) Caldwell, G.; Rozeboom, M. D.; F.; K. J.; Bartmess, J. E. J. Am. Chem. Soc. 1984, 106, 4660 .

(57) Meot-Ner (Mautner), M.; Sieck, L. W. J. Phys. Chem. 1986, 90, 6687.

(58) Asmis, K. R.; Pivonka, N. L.; Santambrogio, G.; Brümmer, M.; Kaposta, C.; Nuemark, D. M.; Wöste, L. Science 2003, 299, 1375.

(59) Marx, D.; Tuckerman, M. E.; Hutter, J.; Parrinello, M. Nature (London) 1999, 397, 601.

(60) Lapid, H.; Agmon, N.; Petersen, M. K.; Voth, G. A. J. Chem. Phys. 2005, 122, 014506 .

(61) Weidemann, E. G.; Zundel, G. Z. Naturforsch. A 1970, 25, 627.

(62) Frank, A. J.; Grätzel, M.; Henglein, A. Ber. Bunsen-Ges. Phys. Chem. 1976, 80, 593.

(63) Agmon, N. J. Phys. Chem. A 2005, 109, 13

(64) Pan, Y.; McAllister, M. A. J. Am. Chem. Soc. 1998, 120, 166.

(65) Lin, J.; Frey, P. A. J. Am. Chem. Soc. 2000, 122, 11258.

(66) Agmon, N. J. Chim. Phys. (Paris) 1996, 93, 1714.

(67) Alfredsson, M.; Ojamäe, L.; Hermansson, K. G. Int. J. Quantum Chem. 1996, 60, 767

(68) Buxton, L. W.; Campbell, E. J.; Flygare, W. H. Chem. Phys. 1981, 56,399 .

(69) Jang, S.; Pak, Y.; Voth, G. A. J. Phys. Chem. A 1999, 103, 10289.

(70) Rey, R.; Hynes, J. T. J. Chem. Phys. 1998, 108, 142.

(71) Handbook of Chemistry and Physics, 3rd electronic ed.; CRC Press Inc.: Boca Raton, FL, 2001.

(72) Zavitsas, A. A. J. Am. Chem. Soc. 1972, 2779.

(73) Pearson, R. G. J. Am. Chem. Soc. 1986, 108, 6109.

(74) Ahrens, M.-L.; Maass, G. Angew. Chem., Int. Ed. 1968, 7, 818

(75) Swain, C. G.; Labes, M. M. J. Am. Chem. Soc. 1957, 79, 1084

(76) Grunwald, E.; Ku, A. Y. J. Am. Chem. Soc. 1968, 90, 29.
(77) Meot-Ner (Mautner), M.; Elmore, D. E.; Scheiner, S. J. Am. Chem. Soc. 1999, 121, 7625 .

(78) Bednar, R. A.; Jencks, W. P. J. Am. Chem. Soc. 1985, 107, 7117

(79) Bednar, R. A.; Jencks, W. P. J. Am. Chem. Soc. 1985, 107, 7126.

(80) Bányai, I.; Blix, J.; Gçaser, J.; Tóth, I. Acta Chem. Scand. 1992, 46,142 .

(81) Bonhoeffer, K. F.; Geib, K. H.; Reitz, O. J. Chem. Phys. 1939, 7 , 664

(82) Bell, R. P.; Goodall, D. M. Proc. R. Soc. (London) 1966, A294, 273

(83) Arnaut, L. G. J. Phys. Org. Chem. 1991, 4, 726.

(84) Pearson, R. G. Acc. Chem. Res. 1993, 26, 250.

(85) Argile, A.; Carey, A. R. E.; Fukata, G.; Harcourt, M.; More O'Ferrall, R. A.; Murphy, M. G. Isr. J. Chem. 1985, 26, 303.

(86) Guthrie, J. P. Can. J. Chem. 1979, 57, 1177.

(87) Ahrens, M.-L.; Eigen, M.; Kruse, W.; Maass, G. Ber. Bunsen-Ges. Phys. Chem. 1970, 74, 380

(88) Peters, K. S.; Kim, G. J. Phys. Chem. A 2004, 108, 2598.

(89) Lee, J.; Robinson, G. W.; Bassez, M.-P. J. Am. Chem. Soc. 1986, 108,7477

(90) Amin, M.; Saunders, W. H., Jr. J. Phys. Org. Chem. 1993, 6, 393. (91) Sugimoto, N.; Sasaki, M.; Osugi, J. J. Phys. Chem. 1982, 86, 3418. (92) Bearne, S. L.; Wolfenden, R. Biochemistry 1997, 36, 1646.

(93) Kresge, A. J.; Mylonakis, S. G.; Sato, Y.; Vitullo, V. P. J. Am Chem. Soc. 1971, 93, 6181.

(94) Wirz, J. Pure Appl. Chem. 1998, 70, 2221.

(95) Marcus, R. A. J. Phys. Chem. 1968, 72, 891.

(96) Cohen, A. O.; Marcus, R. A. J. Phys. Chem. 1968, 72, 4249 371

(97) Koeppl, G. W.; Kresge, A. J. J. Chem. Soc., Chem. Commun. 1973

(98) Formosinho, S. J. J. Chem. Soc., Perkin Trans. 2 1987, 61

(99) Bunting, J. W.; Stefanidis, D. J. Am. Chem. Soc. 1988, 110, 4008.

(100) Yamataka, H.; Nagase, S. J. Org. Chem. 1988, 53, 3232.

(101) Bell, R. P. Discuss. Faraday Soc. 1965, 39, 16.

(102) German, E. D.; Kuznetsov, A. M.; Dogonadze, R. R. J. Chem Soc. Faraday Trans. II 1980, 76, 1128.

(103) German, E. D.; Kuznetsov, A. M. J. Chem. Soc. Faraday Trans. I 1981, 77, 397.

(104) Kresge, A. J. Discuss. Faraday Soc. 1965, 39, 48

(105) Kresge, A. J.; Sagatys, D. S.; Chen, H. L. J. Am. Chem. Soc. 1968 90, 4174

(106) Barnes, D. J.; Bell, R. P. Proc. R. Soc. London 1970, A318, 421

(107) Bell, R. P.; Crooks, J. E. Proc. R. Soc. London 1965, A286, 285

(108) Bordwell, F. G.; Boyle, W. J., Jr. J. Am. Chem. Soc. 1975, 97 3447.

(109) Arnaut, L. G.; Formosinho, S. J. J. Photochem. Photobiol. A Chem. 1993, 75,1

(110) (a) Streitwieser, A., Jr.; Guibé, F. J. Am. Chem. Soc. 1978, 100 4532. (b) Streitwieser, A., Jr.; Ciuffarin, E.; Hammons, J. H. J. Am. Chem. Soc. 1967, 89, 63. (c) The equilibrium acidities of $\mathrm{Li}$ and $\mathrm{Cs}$ cyclohexylamides are much the same, but the former leads to a solvent-separated ion pair.

(111) Streitwieser, A., Jr.; Caldwell, R. A.; Granger, M. R.; Laughton, P. M. J. Phys. Chem. 1964, 68, 2916.

(112) Peters, K. S.; Kim, G. J. Phys. Org. Chem. 2005, 18, 1

(113) Chen, E. C. M.; Wentworth, W. E. J. Chem. Phys. 1975, 63, 3183.

(114) Kebarle, P.; Chowdhury, S. Chem. Rev. 1987, 87, 513.

(115) Wan, P.; Culshaw, S.; Yates, K. J. Am. Chem. Soc. 1982, 104 2509.

(116) McEwen, J.; Yates, K. J. Am. Chem. Soc. 1987, 109, 5800

(117) Förster, T. Pure Appl. Chem. 1970, 24, 443.

(118) Yates, K. J. Phys. Org. Chem. 1989, 2, 300

(119) Arnaut, L. G.; Formosinho, S. J. J. Photochem. Photobiol. A Chem. 1992, 69, 41

(120) Sueishi, Y.; Fujimoto, T.; Yoshida, T.; Kurita, T.; Yamamoto, S.; Nishimura, N. J. Phys. Org. Chem. 1995, 8, 387.

(121) Kallarakal, A. T.; Mitra, B.; Kozarich, J. W.; Gerlt, J. A.; Clifton, J. G.; Petsko, G. A.; Kenyon, G. L. Biochemistry 1995, 34, 2788.

(122) Chiang, Y.; Kresge, A. J.; Pruszynski, P.; Schepp, N. P.; Wirz, J. Angew. Chem., Int. Ed. Engl. 1990, 29, 792.

(123) Chiang, Y.; Kresge, A. J.; Popik, V. V.; Schepp, N. P. J. Am. Chem. Soc. 1997, 119, 10203.

(124) McRae, R. P.; Schenter, G. K.; Garrett, B. C.; Svetlicic, Z.; Truhlar, D. G. J. Chem. Phys. 2001, 115, 8460 .

(125) Kornyshev, A. A.; Kuznetsov, A. M.; Spohr, E.; Ulstrup, J. J. Phys. Chem. B 2003, 107, 3351 .

(126) Laage, D.; Hynes, J. T. Science 2006, 311, 832.

(127) http://www.ism.qui.uc.pt:8180/ism/. The use of this facility is free of charge, does not require a prior registration, and should only cite the present manuscript according to the standard scientific literature. 